PROGRAMA DE DOCTORADO EN CIENCIA E INGENIERÍA AGROALIMENTARIA Y DE BIOSISTEMAS

\title{
TESIS DOCTORAL: \\ ESTUDIO DE MATERIALES PUZOLÁNICOS PARA CONSTRUCCIÓN SOSTENIBLE BASADOS EN RESIDUOS Y SUBPRODUCTOS
}

Presentada por Eduardo Prieto Cobo para optar al grado de

Doctor por la Universidad de Valladolid

Dirigida por:

Dra. Adriana Correa Guimaraes

Dr. Andrés Seco Meneses 

A mi madre

A Ainhoa

A Gonzalo y a Rodrigo 



\section{AGRADECIMIENTOS}

Me gustaría empezar este documento dando las gracias a las personas que me han ayudado a conseguir terminarlo.

A mis directores de Tesis, y a los coautores de los artículos que aporto en esta Tesis por compendio de publicaciones. Sin cuya ayuda, apoyo, dedicación y generosidad no lo habría conseguido.

A mis compañeros de trabajo y a todo mi grupo de investigación, por su apoyo y amistad.

A las familias y amigos de todos los anteriores, por haberme cedido una parte importante de su tiempo y cariño.

A mi familia y amigos, por el tiempo y atención que no les he dado por dedicarlo a la redacción de esta Tesis. Y, en especial, a mi mujer, mis hijos, mi madre, y a Merche y Javier (mis suegros).

A todos los que se alegran conmigo con mis éxitos, y me apoyan en los momentos de necesidad.

Muchas gracias a todos. 



\section{LISTADO DE ABREVIATURAS}

A Aluminio

AAB Ligantes activados alcalinamente (Alkali-Activated Binders)

C Calcio

$\mathrm{C}_{3} \mathrm{~A} \quad$ Aluminato tricálcico

CAH Aluminato de calcio hidratado

CDW Residuo de construcción y demolición (Construction and Demolition Waste)

CS Resistencia a compresión (Compressive Strength)

CSAH Silicoaluminato de calcio hidratado

CSH Silicato de calcio hidratado

EBCM Material de construcción basado en tierra (Earth Based Construction Material)

FA Ceniza volante (Fly Ash)

GGBS Escoria granulada molida de alto horno (Ground Granulated Blastfurnace Slag)

H Hidratado (hidrato)

HR Humedad Relativa

LCA Análisis del ciclo de vida (Life Cycle Analysis)

LCIA Evaluación del impacto del ciclo de vida (Life Cycle Impact Assesment)

NA Áridos naturales (Natural Agreggates)

OMC Contenido de humedad óptimo (Optimum Moisture Content)

OPC Cemento ordinario tipo Portland (Ordinary Portland Cement)

PC Cemento Portland (Portland Cement)

PIB Producto Interior Bruto

RA Áridos reciclados (Recycled Aggregates)

S Silicio

UCS Resistencia a compresión simple (Unconfinated Compressive Strength)

UE Unión Europea

USCS Sistema Unificado de clasificación de suelos (Unified Soil Classification System)

WA Absorción de agua (Water Absortion)

XRD Difracción de rayos-X ( $X$-Ray Diffraction)

XRF Fluorescencia de rayos-X (X-Ray Fluorescence) 



\section{ÍNDICE GENERAL}

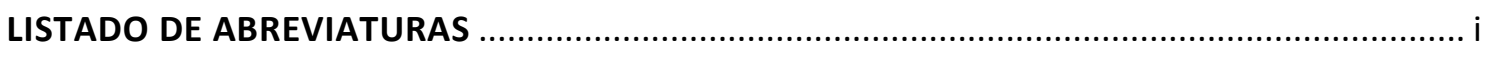

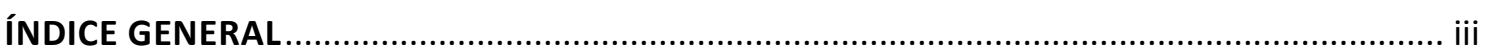

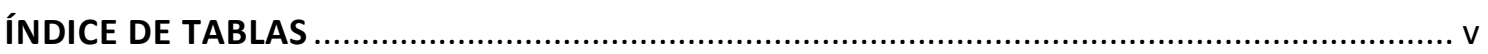

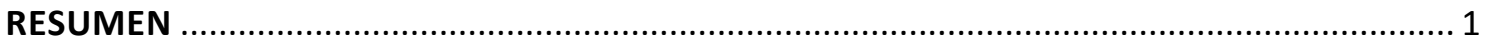

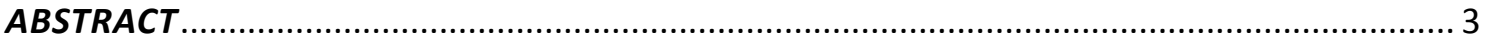

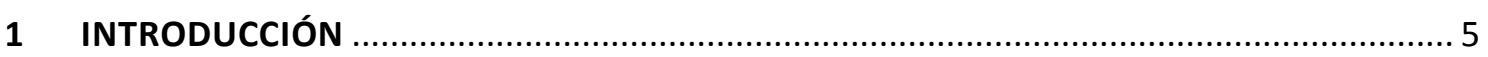

1.1 JUSTIFICACIÓN DE LA RELACIÓN TEMÁTICA DE LAS PUBLICACIONES Y DE LA

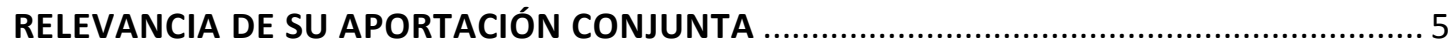

1.1.1 Estabilización de suelos con sulfatos .......................................................... 6

1.1.2 Durabilidad de materiales de construcción basados en tierra ...................... 8

1.1.3 Ladrillos no cocidos a partir de residuos de construcción y demolición .... 10

1.1.4 Morteros con ligantes activados alcalinamente ........................................... 12

1.2 OBJETIVOS GLOBALES PERSEGUIDOS POR LA INVESTIGACIÓN ............................ 14

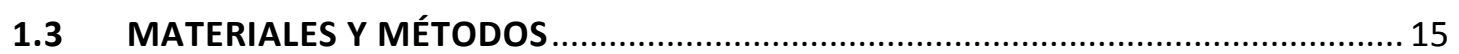

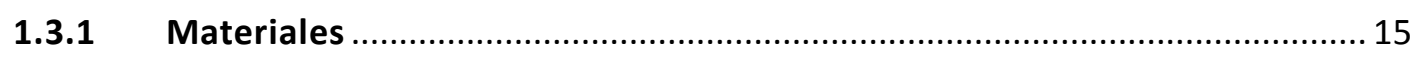

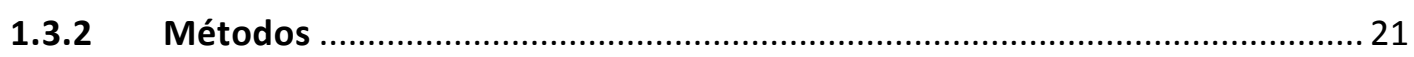

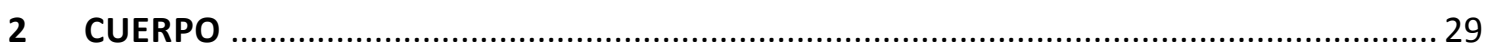

2.1 SULFATE SOILS STABILIZATION WITH MAGNESIUM-BASED BINDERS .................. 30

2.2 ESTIMATED AND REAL DURABILITY OF UNFIRED CLAY BRICKS: DETERMINING FACTORS AND REPRESENTATIVENESS OF THE LABORATORY TESTS ............................ 39

2.3 SUSTAINABLE UNFIRED BRICKS MANUFACTURING FROM CONSTRUCTION AND DEMOLITION WASTES

2.4 TECHNICAL AND ENVIRONMENTAL CHARACTERIZATION OF HYDRAULIC AND

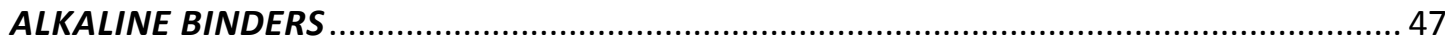

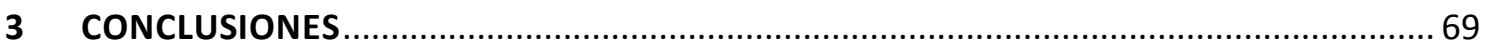

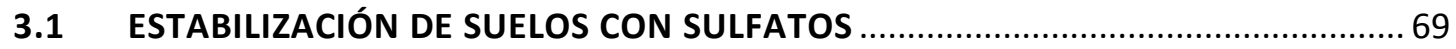

3.2 DURABILIDAD DE MATERIALES DE CONSTRUCCIÓN BASADOS EN TIERRA.......... 71

3.3 LADRILLOS NO COCIDOS A PARTIR DE RESIDUOS DE CONSTRUCCIÓN Y

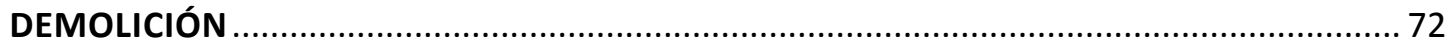

3.4 MORTEROS CON LIGANTES ACTIVADOS ALCALINAMENTE................................... 74

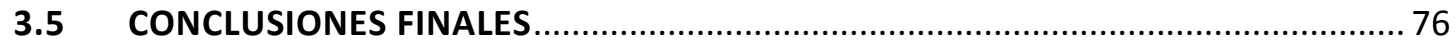

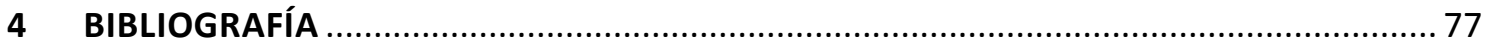




\section{ÍNDICE DE TABLAS}

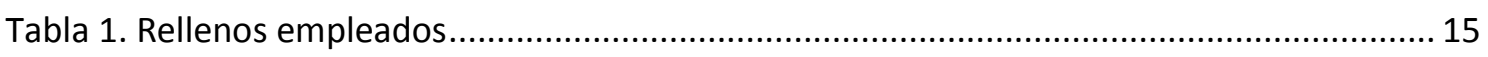

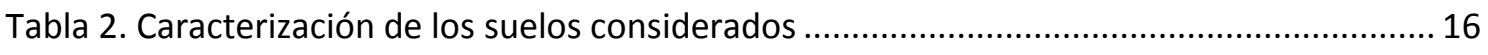

Tabla 3. Caracterización de los residuos para relleno considerados ......................................... 17

Tabla 4. Materiales intencionadamente activos empleados ....................................................... 18

Tabla 5. Excluidos los cementos: Riqueza/composición en óxidos de los ligantes y precursores empleados (\% en masa) y de la producción de $\mathrm{CO} 2$ y consumo de energía de los ligantes

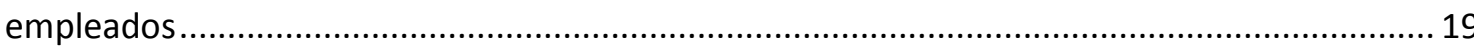

Tabla 6. Composición (\% en peso) de los cementos comunes considerados .............................. 20

Tabla 7. Caracterización de la riqueza química de los cementos expresada en \% en peso de sus

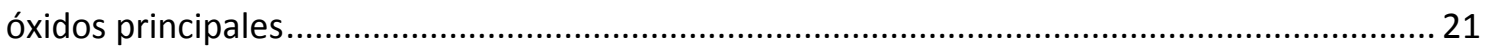

Tabla 8. Composición de las combinaciones con suelos con sulfatos sometidas a ensayos mecánicos (\% en peso) en la primera evidencia (estabilización) .............................................. 22

Tabla 9. Combinaciones ensayadas en la segunda evidencia (durabilidad) ................................ 22

Tabla 10. Proporciones ensayadas de ligantes en la tercera evidencia (CDW) .......................... 23

Tabla 11. Mezclas ensayadas en la investigación del cuarto artículo (\% en peso) (morteros) .. 25 



\section{RESUMEN}

En esta Tesis se estudian varios problemas actuales concretos del mundo de la construcción relacionados con los materiales puzolánicos.

En primer lugar, relacionado con el problema del hinchamiento de los suelos con presencia de sulfatos tratados con cal, se analiza la posibilidad de sustituir este tratamiento por otro basado en el magnesio utilizando un subproducto de la producción de magnesita (PC-8).

En segundo lugar, y también con base en las reacciones propias de los materiales puzolánicos, se estudian dos cuestiones concretas relacionadas con la producción de ladrillos no cocidos. Por un lado, para ladrillos no cocidos, se realiza un análisis de la representatividad de los principales ensayos de laboratorio, con diferentes combinaciones de materiales de relleno con distintos ligantes, y de la durabilidad real de estos materiales de construcción basados en tierra; y por otro, junto al estudio de diferentes ligantes, la valorización de residuos de construcción y demolición, empleándolos en la sustitución de parte de la tierra del relleno de ladrillos no cocidos.

La tercera y última cuestión se ha centrado en comparar la sustitución del cemento Portland por otros ligantes hidráulicos o por ligantes alcalinos.

En el estudio de estabilización de suelos, desde un punto de vista mecánico, en la mayor parte de los casos fueron mejores los resultados con el PC-8 que con cal. Aunque cuando no se empleó escoria granulada molida de alto horno (GGBS), los suelos tratados con PC-8 alcanzaron valores de resistencia similares a los tratados con cal de aproximadamente 2-3 MPa para una dosis de PC-8 o de cal del $4 \%$ y $2-5 \mathrm{MPa}$ para una dosis del $8 \%$. Cuando el PC- 8 se combinó con GGBS los valores de resistencia aumentaron hasta 11-13 MPa, mientras que la cal+GGBS sólo alcanzó los 6-7 MPa. El hinchamiento natural de los suelos tratados con PC-8 disminuyó sustancialmente y se mantuvo constante incluso para la inmersión en agua a largo plazo. En el caso de los suelos tratados con cal, el hinchamiento a largo plazo aumentó hasta valores muy altos, incluso en el caso de suelos sin hinchamiento natural. El análisis de difracción de rayos $X$ de estas muestras demostró, de acuerdo con el comportamiento observado de hinchamiento de los suelos cuando se trataron con ambos aditivos, la existencia de etringita en 4 de los 5 suelos cuando se trataron con cal; y no hubo minerales expansivos en los suelos tratados con PC-8.

Para el estudio de la durabilidad de materiales de construcción basados en tierra, se trató un suelo de marga natural de la Comarca de Pamplona mezclado con diferentes porcentajes de arena de sílice, con cemento Portland, cal hidráulica, una mezcla de cal y GGBS, y PC-8 mezclado con GGBS. Todas las combinaciones se caracterizaron, adaptándolos al estudio de este tipo de materiales, mediante los ensayos de laboratorio habituales relacionados con la durabilidad: densidad máxima, resistencia a la compresión simple, humectación y secado, resistencia a la erosión acelerada de Swinburne, absorción de agua por capilaridad, absorción total de agua y heladicidad. Los resultados de estas pruebas se relacionaron con la durabilidad real de las muestras durante dieciocho meses de exposición al aire libre. Se reveló el efecto positivo de la adición de arena en la durabilidad de los materiales y el gran resultado del ligante a base PC- 8 y GGBS. También se demostró la representatividad de la prueba de absorción de agua como indicador de la durabilidad de los materiales de construcción basados en tierra.

En el caso de la valorización de residuos de construcción y demolición, se emplearon residuos de hormigón y ladrillos cerámicos. Los ladrillos no cocidos producidos se sometieron a ensayos de resistencia a compresión, de heladicidad y de absorción de agua. 
Además, se evaluó el impacto ambiental de la producción de los ladrillos mediante el análisis del ciclo de vida (LCA). Se estableció que los residuos de hormigón podrían usarse para sustituir hasta el $50 \%$ de la arcilla, mientras que los residuos cerámicos sólo podrían sustituir un máximo del $30 \%$ de la arcilla. Se observó que los ladrillos hechos de mezclas de residuos de arcilla y hormigón tenían una resistencia mecánica menor que los hechos de arcilla y residuos cerámicos. En cuanto a la absorción de agua, no hubo apenas diferencia entre ladrillos de las dos mezclas; sin embargo, la reducción en la resistencia a la inmersión en agua fue ligeramente mayor en los ladrillos que contenían residuos de hormigón que en los que contenían residuos cerámicos. Además, los ensayos mostraron que los ladrillos con residuos de hormigón soportan mejor los ciclos de congelación-descongelación que los que contenían residuos cerámicos. El LCA demostró que, en gran medida, es el contenido de ligante en la mezcla lo que determina en gran medida el impacto ambiental de los ladrillos no cocidos producidos. Por último, se demostró que las credenciales técnicas y ambientales más deseables de las mezclas usadas para formar ladrillos resultan del uso de la combinación de los ligantes: CL-90-S+GGBS 2/8.

Para la tercera cuestión principal de esta Tesis, se llevaron a cabo pruebas de consistencia, densidad, resistencia a la compresión y un LCA para establecer la capacidad de sustitución del cemento Portland CEM I de diferentes ligantes hidráulicos y activados alcalinamente. Se consideraron, además del Portland, cuatro cementos comunes con diferentes contenidos de GGBS y cenizas volantes, así como quince combinaciones de ligantes activados alcalinamente. Los resultados obtenidos demostraron la conveniencia técnica y ambiental de estos ligantes alternativos al cemento Portland para la fabricación de morteros de construcción.

Así, los cuatro artículos que forman parte del cuerpo principal de esta tesis presentan una novedosa aplicación combinada de materiales puzolánicos inertes o no (pero no intencionadamente activos) con otros materiales intencionadamente activos para formar materiales de construcción sostenibles y útiles.

Palabras clave: Estabilización de suelos, Materiales de construcción basados en tierra, Análisis del ciclo de vida, Valorización de residuos 


\section{ABSTRACT}

In this thesis several concrete current problems of the construction world related to pozzolanic materials are studied.

In the first place, related to the problem of the swelling of the soils with the presence of sulfates treated with lime, the possibility of replacing this treatment with another one based on magnesium using a by-product of the production of magnesite (PC-8) is analyzed.

Secondly, two specific issues related to the production of unfired clay bricks are studied. On the one hand, for unfired clay bricks, an analysis of the representativeness of the main laboratory tests is carried out, with different combinations of target with different binders, and the real durability of these bricks; and on the other, the recovery of concrete or ceramic brick waste by replacing part of the land with the unfired clay brick target combined with the use of different binders.

The third and last question, developed in this work related to pozzolanic materials, has focused on comparing the replacement of Portland cement with other hydraulic binders or alkaline binders.

In the soil stabilization study, from a mechanical point of view, the soils treated with $P C-8$ reached resistance values similar to those treated with lime, of approximately 2-3 MPa for a dosage of $P C-8$ or lime of the $4 \%$ and 2-5 MPa for a dosage of $8 \%$, the results being generally better with $P C-8$ than with lime. When $P C-8$ was combined with ground granulated blastfurnace slag (GGBS), the resistance values increased to 11-13 MPa and the lime+GGBS reached 6-7 MPa. The natural swelling of soils treated with $P C-8$ decreased substantially and remained constant even for long-term water immersion. In the case of soils treated with lime, long-term swelling increased up to very high values, even in the case of soils without natural swelling. The X-ray diffraction analysis of these samples showed, according to the observed behavior of soil swelling when they were treated with both additives, the existence of ettringite in 4 of the 5 soils when treated with lime; and there were no expansive minerals in the soils treated with $P C-8$.

For the study of the durability of earth based construction materials, a natural marl of the Comarca of Pamplona mixed with different percentages of silica sand, with Portland cement, hydraulic lime, a mixture of lime and GGBS, and mixed PC-8 was treated with GGBS. All combinations were characterized based on the usual laboratory tests related to durability: maximum density, unconfined compressive strength, wetting and drying, Swinburne accelerated erosion resistance, capillarity water absorption, total water absorption and freeze/thawing cycles. The results of these tests were related to the actual durability of the samples during eighteen months of outdoor exposure. The positive effect of the addition of sand on the durability of the materials and the great result of the binder based on PC-8 and GGBS was revealed. The representativeness of the water absorption test was also demonstrated as an indicator of the durability of land-based construction materials.

In the case of the recovery of construction and demolition waste, concrete and ceramic bricks waste were used. The unfired clay bricks produced were subjected to tests of mechanical strength, freeze/thaw resistance and water absorption. Additionally, the environmental impact of brick production was evaluated through the Life Cycle Analysis (LCA). It was established that the concrete waste could be used to replace up to $50 \%$ of the clay, while the ceramic waste could only replace a maximum of $30 \%$ of the clay. It was observed that the bricks made of clay and concrete waste mixtures had a lower mechanical 
strength than those made of clay and ceramic residues. As for water absorption, there was hardly any difference between the two brick mixtures; however, the reduction in the resistance to immersion in water was slightly greater in the bricks containing concrete residues than in those containing ceramic residues. In addition, the tests showed that the resistance to freezing-thawing was greater in bricks mixed with concrete residues than in those that incorporated ceramic residues. LCA demonstrated that it is the binder content in the mix that largely determines the environmental impact of blended bricks produced. Lastly, it was shown that the most desirable technical and environmental credentials of the brick material mixes resulted from using the binder combination: CL-90-S + GGBS 2/8.

For the third main issue of this thesis, tests of fresh consistency, density, compressive strenght and an LCA were carried out to state the ability of these different hydraulic and alkaline activated binders from the Portland Cement CEM I substitution. Four common cements with different contents of GGBS and fly ashes (FA) were considered, as well as fifteen alkaline activated binders combinations. The results obtained demonstrated the technical and environmental convenience of these alternative binders to Portland cement for the construction mortars manufacturing.

Thus, the four articles that are part of the main body of this doctoral thesis present an innovative use of pozzolanic materials inert or not (but not intentionally active) with other intentionally active materials to form sustainable and useful building materials.

Keywords: Soil stabilization, Earth based construction materials, Life Cycle Analysis, Waste valorization 


\section{INTRODUCCIÓN}

En esta Introducción, y tal y como establece la normativa de la Universidad de Valladolid para las tesis doctorales presentadas bajo la modalidad de compendio de publicaciones, se justifica la relación temática de las publicaciones.

Siguiendo también la normativa de la Universidad de Valladolid, se describen los objetivos globales perseguidos por la investigación y la metodología empleada.

\subsection{JUSTIFICACIÓN DE LA RELACIÓN TEMÁTICA DE LAS PUBLICACIONES Y DE LA RELEVANCIA DE SU APORTACIÓN CONJUNTA}

Esta tesis doctoral trata el tema de la aplicación de los materiales puzolánicos para la construcción sostenible basados en residuos y subproductos. Está presentada como compendio de artículos, y se basa en cuatro artículos sobre la misma temática publicados en diferentes revistas del Q1 de su categoría del JCR.

Estos cuatro artículos se presentan de manera cronológica a su publicación que coincide con el desarrollo temporal lógico de la investigación presentada, en la que todos los artículos tienen en común, además de materiales de partida y métodos, la finalidad de conseguir materiales de construcción más sostenibles que los habitualmente empleados.

El primero de los artículos está dedicado a la estabilización de suelos con problemas de hinchamiento debidos a la presencia de sulfatos. Para estabilización de estos suelos se utilizarán métodos clásicos basados en la utilización de calcio, y se compararán con los estabilizados a base de un subproducto de la producción de magnesita rico en magnesio denominado PC-8.

En el segundo artículo, en el que se utilizan materiales ya empleados en el primero (suelo de marga, ligantes que aportan cal y PC-8), junto al cemento y la arena para fabricar ladrillos no cocidos y estudiar su durabilidad real.

El tercer artículo profundiza aún más en el tema de los ladrillos no cocidos estudiando la sustitución de parte de los materiales de primer uso empleados en su fabricación (principalmente suelos utilizados como relleno) por materiales procedentes de residuos de construcción (hormigón y ladrillos cocidos).

El cuarto artículo completa el estudio comenzado en el artículo anterior, más enfocado en los rellenos, al centrarse en los ligantes.

En resumen, los cuatro artículos que introduzco a continuación presentan una novedosa aplicación combinada de materiales puzolánicos inertes o no (pero no intencionadamente 
activos) con otros materiales intencionadamente activos para formar materiales de construcción sostenibles y útiles.

\subsubsection{Estabilización de suelos con sulfatos}

La estabilización con calcio o cemento de suelos es una técnica ampliamente utilizada para mejorar las propiedades de los suelos como material de construcción. El uso de estos aditivos es particularmente adecuado en suelos arcillosos, que usualmente tienen propiedades inadecuadas como alta plasticidad, mala trabajabilidad y baja capacidad de carga (Göktepe et al., 2008; Guney et al. 2007; Lin et al., 2007).

Los suelos arcillosos están formados por minerales con capas de aluminosilicato de carga superficial negativa que, por repulsión electrostática, mantienen una estructura abierta. Con la adición de la cal, se produce la fijación de iones $\mathrm{Ca}^{2+}$, se equilibran las cargas electrostáticas de las capas de arcilla y se reducen las fuerzas de repulsión electroquímicas entre ellas. Esto causa la adhesión de las partículas de arcilla donde las capas de sus minerales se unen en flóculos mediante iones de $\mathrm{Ca}^{2+}$, lo que da como resultado un suelo con propiedades mejoradas: una estructura más granular, una mayor permeabilidad y una plasticidad menor (Kinuthia et al., 1999; Lin et al., 2007).

Además, la hidratación de la cal al liberar iones $\mathrm{OH}^{-}$aumenta el $\mathrm{pH}$ hasta aproximadamente 12.4. En estas condiciones, se producen reacciones puzolánicas en el suelo: el aluminio (A) y el silicio (S) de la matriz de arcilla se solubilizan y se combinan con el calcio disponible (C) generando compuestos cementantes hidratados $(\mathrm{H})$ denominados silicato de calcio hidratado (CSH), aluminato de calcio hidratado (CAH) y silicoaluminato de calcio hidratado (CSAH) (L. Chen y Lin, 2009; Guney et al., 2007; Nalbantoğlu, 2004; Yong y Ouhadi, 2007). Estos compuestos son responsables de la mejora de las propiedades mecánicas del suelo estabilizado después del curado, por el desarrollo de las reacciones puzolánicas. La cinética de estas reacciones depende de la cantidad y disponibilidad de los óxidos implicados y pueden llegar a durar años (Wild et al., 1998).

La matriz de arcilla usualmente tiene suficiente aluminio y silicio para permitir el uso de cal en lugar de cemento, siendo éste un tratamiento más barato y eficaz (L. Chen y Lin, 2009). En aquellos suelos donde no hay suficiente silicio y aluminio disponibles, estos elementos deben agregarse como aditivos. En estos casos, se recomienda el uso de productos como el cemento Portland (OPC), rico en $\mathrm{SiO}_{2}, \mathrm{Al}_{2} \mathrm{O}_{3}$ y $\mathrm{CaO}$, para proporcionar los óxidos necesarios, acortando también el tiempo de reacción (Degirmenci et al., 2007; Wild et al., 1998).

La mejora de las propiedades obtenidas dependerá de la cantidad y riqueza del aditivo, la mineralogía del suelo, el tamaño y la forma de las partículas y las condiciones de curado (Göktepe et al., 2008; Misra et al., 2005; Yarbaşı el al., 2007).

A pesar de la demostrada idoneidad técnica, económica y ambiental del uso de aditivos basados en calcio como estabilizadores para los suelos, este tipo de tratamiento puede causar efectos adversos en algunos suelos, e incluso provocar la destrucción total del material estabilizado. Una de las causas más comunes de este tipo de fallos es la presencia en el suelo 
estabilizado de sulfatos $\left(\left(\mathrm{SO}_{4}\right)^{2-}\right)$. El sulfato es un óxido muy común, tanto en los suelos naturales de todo el mundo, como en los residuos industriales. Otras veces, el sulfato, puede provenir del agua utilizada para la compactación o surgida por infiltración del terreno circundante. Cualquiera que sea su origen, la reacción conjunta del calcio (suministrado por la cal o el cemento), el aluminio, el silicio y el sulfato en presencia de agua puede provocar la formación de minerales expansivos. El más común, y habitualmente más peligroso, es un mineral cristalino altamente hidratado y expansivo llamado etringita: $\mathrm{Ca}_{6} \mathrm{Al}_{2}\left(\mathrm{SO}_{4}\right)_{3}(\mathrm{OH})_{12} \cdot 26 \mathrm{H}_{2} \mathrm{O}$ (Ciliberto et al., 2008; Crammond, 2002; Nobst y Stark, 2003; Norman et al., 2013).

Se sabe que la velocidad de formación de etringita se acelera cuando las temperaturas son altas (Rajasekaran, 2005). Talero (2005) y Rahhal y Talero (2014) señalaron diferentes tasas de formación, forma y tamaño de los cristales de etringita basados en diferentes compuestos de aluminio reactivos procedentes del cemento Portland -como el aluminato tricálcico $\left(C_{3} A\right)-y$ adiciones de puzolana $\left(\left(\mathrm{Al}_{2} \mathrm{O}_{3}\right)^{\mathrm{r}}\right)^{-}$.

Con las condiciones adecuadas la formación de etringita es la reacción dominante, e incluso aparece durante la mezcla de los materiales. Mohamed (2000) determinó que el tiempo total de formación de etringita en un suelo de marga natural era inferior a las $48 \mathrm{~h}$.

En sus experimentos, Ouhadi y Yong $(2003 ; 2008)$ establecieron la formación de este mineral en la mezcla de suelo con cal entre $48 \mathrm{~h}$ y un mes.

La mecánica de la formación de etringita no está bien establecida (Mohamed, 2000), aunque se conocen las condiciones para su formación (Ouhadi y Yong, 2003 y 2008), que son:

1. Presencia de agua $\left(\mathrm{H}_{2} \mathrm{O}\right)$ : necesaria para la hidratación de la cal viva para formar $\mathrm{Ca}(\mathrm{OH})_{2}$, la disolución de los hidróxidos de aluminio en $\mathrm{pH}$ alto y la de los minerales con sulfatos del suelo, y la formación final de la etringita.

2. $\mathrm{pH}$ alto $\left(\mathrm{OH}^{-}\right)$: necesario para la disolución del aluminio, producido por la ionización del $\mathrm{Ca}(\mathrm{OH})_{2}$.

3. Presencia de Al soluble $\left(\mathrm{Al}(\mathrm{OH})_{4}^{-}\right)$: generado por la presencia de agua en $\mathrm{pH}$ alto.

4. Presencia de Ca soluble $\left(\mathrm{Ca}^{2+}\right)$ : generado por ionización del $\mathrm{Ca}(\mathrm{OH})_{2}$.

5. Presencia de sulfato soluble $\left(\left(\mathrm{SO}_{4}\right)^{2-}\right)$ : generado por disolución de los minerales con sulfatos.

Cuando se dan las cinco condiciones anteriores, podría producirse etringita según la siguiente reacción (Ec. [1]):

$$
6 \mathrm{Ca}^{2+}+2 \mathrm{Al}(\mathrm{OH})^{4-}+4 \mathrm{OH}^{-}+3\left(\mathrm{SO}_{4}\right)^{2-}+26 \mathrm{H}_{2} \mathrm{O} \rightarrow \mathrm{Ca}_{6} \mathrm{Al}_{2}\left(\mathrm{SO}_{4}\right)_{3}(\mathrm{OH})_{12}, 26 \mathrm{H}_{2} \mathrm{O} \quad \text { Ec. [1] }
$$

Se ha observado una segunda manera más lenta de formación de etringita en morteros y hormigones de OPC donde, después de largos períodos de curado en condiciones de humedad, el sulfato ataca a los $\mathrm{CAH}$, generando lo que comúnmente se conoce como "etringita retardada", que provoca los mismos efectos indeseables en los materiales ligados (J. Chen y Jiang, 2009; Ciliberto et al., 2008; Escadeillas et al., 2007; Lee et al., 2005; Nguyen et al., 2013; Pavoine et al., 2012). 
La capacidad de hinchamiento del suelo en el que se desarrolla etringita, y por lo tanto sus efectos indeseables, se produce durante la formación de esta mineral. Una vez que la etringita está presente en el suelo es estable, e incluso contribuye a mejorar su capacidad de carga (Kinuthia et al., 1999; Min et al., 2008; Rajasekaran, 2005).

Una forma de reducir la formación de etringita en un suelo con sulfato estabilizado es la sustitución parcial de cal o cemento por escoria granulada molida de alto horno (GGBS). La GGBS contribuye con una gran cantidad de aluminio y silicio rápidamente disponibles, los cuales reaccionan con el calcio disponible y lo consumen formando geles ligantes, evitando la formación de etringita. Este efecto protector contra el ataque por sulfato es especialmente intenso para altas proporciones de reemplazo de la cal por GGBS (aproximadamente 83\%). Además, la GGBS también produce una matriz cementosa más densa, reduce la permeabilidad $y$, por lo tanto, la posibilidad de contacto con el agua, aumentando la durabilidad frente al ataque interno y externo por sulfato (Obuzor et al., 2012; Tasong et al., 1999; Wild et al., 1998). Sin embargo, esta forma de limitar el ataque por sulfato debe usarse con cuidado porque todos los óxidos necesarios para la formación de etringita permanecen en el material tratado (Celik y Nalbantoglu, 2013).

Otra forma posible para estabilizar los suelos con sulfatos puede ser la sustitución de los aditivos basados en calcio por otros cationes metálicos, como el magnesio. Xeidakis (1996a, 1996b) demostró que la fijación de $\mathrm{Mg}(\mathrm{OH})_{2}$ en las capas de arcilla expansiva es más rápida que la de $\mathrm{Ca}(\mathrm{OH})_{2}$, lo que genera también en la floculación de la arcilla. También demostró la capacidad del $\mathrm{Mg}(\mathrm{OH})_{2}$ para aumentar el $\mathrm{pH}$ del suelo y la posibilidad teórica de producir geles ligantes a base de $\mathrm{Mg}$.

La falta de garantías sobre la estabilización de los suelos de sulfato con aditivos de calcio, la capacidad de magnesio para flocular las arcillas y sus propiedades eventualmente cementantes, hace que los aditivos a base de magnesio sean un tema de investigación muy interesante. Además, la inestabilidad, a medio o largo plazo, de algunos suelos estabilizados señala el interés de estudiar el comportamiento a lo largo del tiempo de estas estabilizaciones, y de la durabilidad de los materiales de construcción basados en tierra (ECBM).

\subsubsection{Durabilidad de materiales de construcción basados en tierra}

La construcción de edificios con EBCM es una técnica extendida por todo el mundo desde hace más de 9000 años, y actualmente todavía se usa en la mayoría de los países en vías de desarrollo. El éxito de estos materiales se basa en la fácil disponibilidad de las materias primas, su simplicidad de ejecución, sus buenas propiedades térmicas y acústicas, y su economía (Oti et al., 2009a, 2010).

En los países desarrollados, este sistema de construcción tradicional fue prácticamente abandonado desde el comienzo del siglo XX en favor de materiales más modernos, cuando los avances tecnológicos y la capacidad económica generalizaron el uso, por ejemplo, de ladrillos cocidos y bloques de hormigón. Sin embargo, desde el comienzo del siglo XXI, los intereses cada vez mayores en la recuperación de los EBCM también se han notado en los países desarrollados. Esto se debe, entre otras razones, a su baja huella de carbono, bajo consumo de energía, la 
capacidad de ser producidos a partir de subproductos y residuos, sus buenas propiedades técnicas y condiciones ambientales para sus usuarios en los edificios hechos con ellos (Ciancio et al., 2013; Ferreira et al., 2015; Labat et al., 2016; Miqueleiz et al., 2012, 2013; Muntohar, 2011; Raut et al., 2011; Seco et al., 2012).

A pesar de todas estas ventajas, los EBCM tienen el inconveniente de una alta afinidad por el agua, lo que provoca el deterioro de las propiedades resistentes y podría afectar a su durabilidad (Aubert et al., 2013; Cid-Falceto et al., 2012; Oti et al., 2009a, 2009b; Uranjek y Bokan-Bosiljkov, 2015).

Estos efectos indeseables se han resuelto tradicionalmente mediante el uso de aditivos cementantes, una alta energía de compactación, la modificación granulométrica del suelo y el aislamiento de estos materiales del agua. El uso de aditivos cementantes es una forma efectiva y económica de mejorar las propiedades constructivas del material, debido a la formación de geles cementantes que desarrollan una matriz resistente alrededor de las partículas del suelo. Esto aumenta la densidad del suelo tratado, mejorando el contacto entre las partículas, aumentando así sus propiedades mecánicas (Muntohar, 2011; Oti et al., 2009b).

Además, los aditivos cementantes utilizados mejoran la trabajabilidad de los suelos de arcilla al disminuir su plasticidad (Kinuthia y Oti, 2012; Seco et al., 2011a) y disminuyen la capacidad de movimiento del agua, mejorando su durabilidad (Alam et al., 2015; Li et al., 2015; Naganathan et al., 2015).

El uso de una alta energía de compactación en la fabricación mejora el contacto entre las partículas, aumenta la densidad del material y reduce el tamaño y la cantidad de poros. Esto mejora las propiedades mecánicas de las partículas y contribuye a que sean menos susceptibles a los efectos del agua (Cid-Falceto et al., 2012).

En relación con la conveniencia de la modificación granulométrica, no se ha llegado a un acuerdo de expertos: muchos autores consideran que la adición de arena a los suelos con los que se fabrican estos materiales permite mejorar sus propiedades, ya que aumenta la densidad del producto y disminuye la cantidad y tamaño de los poros de la mezcla, lo que podría ser un indicador indirecto de buenas propiedades mecánicas y durabilidad. En este sentido, diferentes manuales y estudios publicados recomiendan añadir diferentes proporciones de arena a arcilla.

Por ejemplo, Muntohar (2011) afirmó que la proporción óptima de suelo/arena era del 70/30 para obtener la mayor resistencia a la compresión, la mayor densidad y la menor permeabilidad en un suelo estabilizado.

Ciancio et al. (2013) sometieron a prueba diez mezclas de suelo para la construcción de tierra apisonada estabilizada y no estabilizada con cemento. En estas mezclas los contenidos de arcilla y arena fueron de $5-40 \%$ y $20-60 \%$ respectivamente. Descubrieron, en base a la resistencia a la compresión simple, y los ensayos de contracción acelerada y de secado, que seis de las mezclas eran adecuadas para este propósito. Sin embargo, las cuatro mezclas con el mayor contenido de arcilla no fueron adecuadas. 
Por otro lado, algunos autores que trabajan con suelos arcillosos puros lograron materiales con altas propiedades mecánicas y durabilidad. Oti y Kinuthia (2012) y Oti et al. (2009a) estabilizaron suelos puros del Lower Oxford Clay con cemento Portland y cal más GGBS. Obtuvieron valores de resistencia a la compresión simple superiores a $5 \mathrm{MPa}$ y una mayor pérdida de peso del ensayo de heladicidad (AENOR, 1997) del 1,9\%.

Esto muestra la complejidad de interpretar el efecto de la arena sobre el contenido de arcilla en la estabilización de un suelo, y la dificultad de extrapolación de los resultados de un estudio a otro.

De todos modos, se ha afirmado que la adición de arena permite una mejor trabajabilidad del suelo y la reducción del hinchamiento y contracción cuando se usan suelos muy plásticos (Ciancio et al., 2013).

Finalmente, en la fabricación de EBCM es importante considerar la posibilidad de utilizar productos tales como enlucidos o impermeabilizantes, que eviten que el agua entre en el material. Lo anterior, claro está, junto con la elección adecuada del tipo y la cantidad de aditivo cementante, la energía de compactación y el tamaño de partículas del suelo.

Aunque no hay consenso en este sentido, las relaciones entre resistencia, densidad y durabilidad son normalmente empleadas en el diseño de la composición y en la selección de los parámetros de fabricación de los EBCM. Esta es la razón por la cual la caracterización técnica de estos materiales se basa en ensayos de resistencia mecánica y de propiedades relacionadas con el agua, a partir de las cuales se estima su durabilidad. Esta forma de estimación de la durabilidad, comúnmente utilizada en materiales de construcción convencionales, ha demostrado ser poco fiable en el caso de los EBCM, subestimándola muchas veces, cuando se compara con la durabilidad real de estos materiales (Guillaud y Houben, 2006).

\subsubsection{Ladrillos no cocidos a partir de residuos de construcción y demolición}

El sector de la construcción tiene una importancia estratégica para la economía global. Sólo en la Unión Europea, la construcción genera alrededor del 10\% del Producto Interior Bruto (PIB), proporciona 20 millones de empleos y tiene gran impacto en la calidad de vida de la población (Cambridge Econometrics, 2014).

Las infraestructuras, la construcción de edificios y las actividades de demolición consumen alrededor del $50 \%$ de las materias primas y representan el $33 \%$ de los 900 millones de toneladas de residuos generados cada año en la Unión Europea (UE) (Bravo et al., 2015; Cambridge Econometrics, 2014).

No existe una composición particular de los residuos de construcción y demolición (CDW) ya que varían según el tipo de estructura y/o proceso de demolición y sistema de gestión de la construcción empleados. Generalmente los CDW típicamente incluyen (F. Pacheco-Torgal, 2014):

1. hormigón estructural, 
2. ladrillos, azulejos y cerámicas de pisos, techos y tabiques y,

3. en menores cantidades, otros materiales como vidrio, madera, placas de yeso, asbesto, metal, plástico o materiales peligrosos. La mayoría de estos residuos generalmente se eliminan en vertederos sin ningún tipo de recuperación o reutilización, lo que genera importantes problemas económicos y ambientales.

La UE (2008) ha reconocido la necesidad de una gestión sostenible del uso de los recursos naturales y de los residuos. En consecuencia, se han establecido objetivos para aumentar la reutilización, la recuperación y el reciclado de los CDW no peligrosos en toda Europa, desde la tasa promedio actual del 47\% hasta más del 70\% en 2020.

Existe un gran potencial para la reutilización y el reciclado de CDW ya que la mayoría de sus componentes pueden tener compuestos de alto valor como recurso. Como cada tipo de material requiere formas específicas para su valorización, los sistemas de gestión más efectivos sugieren el uso de técnicas apropiadas de demolición combinadas con el reciclaje y la reutilización. De esta forma, el vidrio, la madera, el asbesto, los metales, los plásticos, los materiales peligrosos, etc. pueden separarse de la parte principal compuesta por residuos inertes, que en su mayoría son restos de hormigón y mampostería (Vegas et al., 2015; Vieira et al., 2016).

Dichos materiales residuales pueden procesarse fácilmente como áridos reciclados (RA) para su uso en lugar de los áridos naturales (NA. Los ejemplos de uso de RA incluyen la construcción de capas de firmes ligadas y sin ligar (cementadas y sin cementar) y la producción de hormigón reciclado (Özalp et al., 2016; Xuan et al., 2015, 2016).

Estas aplicaciones están limitadas en la práctica debido a la menor calidad y durabilidad percibidas de los RA en comparación con los NA. Debido a eso, es una práctica común excluir las partículas finas de los RA y limitar la proporción máxima de su fracción gruesa de los RA añadida a los NA (Bravo et al., 2015; Butera et al., 2015; Cardoso et al., 2016; Grist et al., 2015; Ledesma et al., 2015; Rodríguez et al., 2016; Silva et al., 2014).

Por ejemplo, la norma europea EN 12620 (CEN, 2009) permite, para la fabricación de hormigón, un tamaño de grano superior a $4 \mathrm{~mm}$ para el uso de RA con NA.

La norma española EHE-08 (España. Ministerio de la Presidencia, 2008), en su anejo 15, recomienda limitar, para su aplicación en hormigón estructural, el contenido de RA grueso al $20 \%$ en peso sobre el contenido total de árido grueso.

Otras formas posibles para la valorización de RA incluyen la sustitución parcial del suelo arcilloso natural por estos residuos, en la producción de ladrillos sin cocer (Li et al., 2015; Liu et al., 2011; Miqueleiz et al., 2013; Oti y Kinuthia, 2012; L. Zhang, 2013).

También hay algunas propiedades de los RA que podrían mejorar aún más la sostenibilidad de los ladrillos no cocidos. Por ejemplo, el uso de la fracción más fina de RA para reemplazar algunos materiales naturales o usarse directamente, sin tratamiento previo, en la fabricación de otros productos. Los minerales en los RA pueden ser químicamente inertes, sin embargo, la presencia de cualquier material cerámico residual puede producir algunas propiedades puzolánicas (Oti et al., Kinuthia y Robinson, 2014; Schackow et al., 2015). En cuanto 
al hormigón, podría contener pequeñas cantidades de cemento residual que aún podría ser reactivo. Por lo tanto, esto podría potencialmente sustituir al ligante de primer uso en las nuevas construcciones, o permitir el reemplazo de ligantes menos sostenibles (como el cemento) por éstos más sostenibles (Bravo et al., 2015; Vieira et al., 2016). Esta idea, sobre la diferente sostenibilidad de los ligantes empleados en los EBCM, señala también el interés de estudiar la sostenibilidad de estos ligantes.

\subsubsection{Morteros con ligantes activados alcalinamente}

El cemento Portland (PC) es un polvo inorgánico finamente molido, no metálico, obtenido de la calcinación de rocas naturales que, cuando se mezcla con agua, forma una pasta que fragua y endurece. EI PC es el ligante hidráulico más utilizado en todo el mundo, desde su invención en el siglo XIX, para construcción y edificación. Hoy en día es un producto esencial debido a sus buenas propiedades mecánicas, durabilidad y costo relativamente bajo (Babaee y Castel, 2016; Juenger et al., 2011).

Así, la fabricación de hormigón, morteros y enlucidos, la estabilización de suelos o la construcción de capas acotadas de pavimento, entre otras aplicaciones, consumen grandes cantidades de este ligante. Sólo en la Unión Europea, la industria del cemento, en 2011 produjo 195.5 Mt, lo que representó el 5.6\% de la producción mundial total (European Commission, 2018a).

A pesar de la conveniencia de este material, el sector del cemento tiene que abordar el importante desafío de su falta de sostenibilidad: La fabricación de PC es un proceso intensivo de producción de energía que consume una energía de aproximadamente entre 3500 y $5000 \mathrm{MJ} / \mathrm{t}$ de PC y produce entre 0,9 y 1 toneladas de $\mathrm{CO}_{2} /$ tonelada de PC (Maddalena et al., 2018; Fernando Pacheco-Torgal et al., 2008; Schorcht et al., 2013).

Esto supone aproximadamente el 2-3\% del uso de energía primaria mundial y el 5-10\% del total de emisiones antropogénicas de $\mathrm{CO}_{2}$ (Bellmann y Stark, 2009; Damtoft et al., 2008; Habert et al., 2011; Maddalena et al., 2018; Teh et al., 2017).

En la actualidad, la fabricación de cemento tiende hacia formas de producción más bajas en emisiones de carbono y más eficientes desde el punto de vista energético, de acuerdo con las actuales demandas sociales y tendencias de las políticas económicas, políticas climáticas y energéticas (European Commission, 2018b).

Una forma efectiva de mejorar la sostenibilidad de PC es su sustitución parcial por aditivos con menor impacto ambiental. Por ejemplo, la Norma Europea EN 197-1 (CEN, 2011a), considera la sustitución, de hasta el $80 \%$, del clinker por diferentes productos para la fabricación de cementos comunes. Estos son materiales ricos en óxidos reactivos de silicio y aluminio, que por sí mismos poseen poco o ningún valor cementante pero que, finamente molidos, reaccionan con el óxido de calcio presente en el PC para formar compuestos cementantes. Alguno de estos aditivos son residuos o subproductos de la industria, como las GGBS y las cenizas volantes (FA), que se utilizan, para contribuir a su valorización, en la fabricación de cemento (Aïtcin, 2014; O'Brien et al., 2009; Prusinski et al., 2006; Seco et al., 2012). 
Como estos aditivos normalmente no requieren ser calcinados, su uso no sólo es una forma efectiva de ahorrar recursos naturales sino que también contribuye a disminuir las emisiones de $\mathrm{CO}_{2}$ (Maddalena et al., 2018; Prusinski et al., 2006).

Además, muchos de los cementos que contienen estos productos pueden mostrar mejores propiedades en comparación con el cemento Portland, como mayor resistencia mecánica, mayor resistencia a ambientes agresivos o mayor durabilidad (Andrade y Buják, 2013; Le Saoût et al., 2013; Lorca et al., 2014).

Otra forma de mejorar la sostenibilidad en esas aplicaciones, donde el cemento es ampliamente utilizado, es su sustitución por ligantes de menor impacto ambiental. Así, los ligantes activados alcalinamente ( $A A B)$ reciben cada vez más atención como posibles alternativas al PC, debido a su potencial, basado en sus propiedades mecánicas generalmente altas, adecuada durabilidad y menor impacto ambiental de fabricación (Ouellet-Plamondon y Habert, 2015; Phoo-ngernkham et al., 2018; Provis, 2017; C. Shi y Jiménez, 2011; Turner y Collins, 2013; Z. Zhang et al., 2016).

Estos ligantes están compuestos de un material precursor, rico en óxidos reactivos de silicio y aluminio, y una solución de activador alcalino. En las condiciones de $\mathrm{pH}$ alto creadas por el activador, se crean polímeros cementantes de silicio y aluminio denominados geopolímeros (Provis, 2017; X. Shi et al., 2011).

Las características de los $A A B$ dependen de las propiedades del precursor y del activador, existiendo muchas publicaciones que demostraron su buena resistencia mecánica, baja permeabilidad y alta durabilidad (Hanjitsuwan et al., 2018; Khan et al., 2016; Mobili et al., 2016; Passuello et al., 2017; Phoo-ngernkham et al., 2016; Provis, 2017; Puertas et al., 2015; Z. Zhang et al., 2016).

Al igual que en el caso de los cementos hidráulicos con adiciones, diferentes subproductos y residuos pueden usarse como precursores de los $A A B$, lo que contribuye a resaltar las mejores características ambientales de estos ligantes en comparación con el PC (McLellan et al, 2011). 


\subsection{OBJETIVOS GLOBALES PERSEGUIDOS POR LA INVESTIGACIÓN}

Esta investigación tiene como objeto el estudio de materiales puzolánicos pueden tener potencial para ser empleados en el sector de la construcción con residuos, subproductos o materiales con menor impacto ambiental que los habitualmente empleados.

El primer objetivo de esta investigación es evaluar la posibilidad de estabilizar los suelos que contienen sulfato, en lugar de los basados en calcio, con aditivos a base de magnesio. En concreto con el empleo de un subproducto de la producción de magnesita denominado PC-8.

El segundo objetivo es realizar un estudio experimental que determine el efecto de los principales parámetros de fabricación de los materiales de construcción basados en tierra que afectan la durabilidad, comparando los resultados de laboratorio con los que se han obtenido en condiciones de uso a la intemperie. Se trata de establecer la fiabilidad de diferentes ensayos de laboratorio para predecir la durabilidad real de un tipo concreto de estos materiales, que son los ladrillos no cocidos (unfired clay bricks). Esto se hará para ladrillos fabricados con ligantes habituales y con un ligante a base de GGBS+PC-8.

El tercer objetivo de este trabajo es el examen de la idoneidad, combinándolos con diferentes ligantes (binders), del uso de la fracción fina de dos residuos de construcción y demolición: hormigón y ladrillos cocidos usados triturados, en la producción de ladrillos sin cocer, como relleno (target). Se trata de determinar, tanto el ligante más efectivo y dosificación de las proporciones de relleno de la mezcla más adecuadas, como el impacto ambiental de cada combinación estudiada.

El cuarto objetivo es estudiar sus características de fraguado, consistencia en fresco y de resistencia a compresión. Además de comparar, desde el punto de vista ambiental, la sustitución en los morteros del cemento Portland CEM I por otros ligantes hidráulicos y por ligantes activados alcalinamente. La caracterización ambiental de las muestras se realizará mediante la metodología del Análisis de Ciclo de Vida con y sin estandarización de los resultados en función de las propiedades mecánicas de los ligantes. 


\subsection{MATERIALES Y MÉTODOS}

\subsubsection{Materiales}

En los cuatro artículos que forman el cuerpo de esta Tesis se emplean dos tipos de materiales básicos de partida:

- Los llamados rellenos o targets

- Los materiales intencionadamente activos, que -según el contexto- en unos casos se llamaran aditivos, en otros ligantes o binders, y en otros precursores o activadores.

\section{Rellenos}

Los rellenos (targets) empleados, el tipo de material, y la evidencia (artículo) en el que se emplean, se indican en la Tabla 1.

\begin{tabular}{|l|c|c|}
\hline Relleno & Tipo de material & Evidencia \\
\hline Suelo I & Suelo natural & 1 \\
\hline Suelo II & Suelo natural & 1 \\
\hline Suelo III & Suelo natural & 1 \\
\hline Marga & Suelo natural & $1,2,3$ \\
\hline Escoria de biomasa & Residuo & 1 \\
\hline Hormigón estructural & Residuo & 1,3 \\
\hline Ladrillo cocido & Residuo & 3 \\
\hline Arena & Producto & 2,4 \\
\hline
\end{tabular}

Tabla 1. Rellenos empleados

Como se puede ver en la Tabla 1 se emplearon 4 tipos de rellenos: suelos naturales, residuos y un producto (arena).

En este estudio se consideraron cuatro suelos naturales (I, II, III y la marga). La Tabla 2 muestra la caracterización de los suelos analizados desde los puntos de vista mecánico y químico. Los suelos, expansivos y con diferentes contenidos de sulfato, I, II y III se obtuvieron de diferentes formaciones geológicas terciarias a lo largo del Valle del Ebro en el norte de España. La marga utilizada para este trabajo fue una muestra de marga gris de la región de Pamplona, también en el Norte de España. 


\begin{tabular}{|c|c|c|c|c|}
\hline NOMBRE & SUELO I & SUELO II & SUELO III & MARGA \\
\hline \multicolumn{5}{|l|}{ Coordenadas WGS84: } \\
\hline Latitud & $42^{\circ} 10^{\prime} 14,75^{\prime \prime} \mathrm{N}$ & $410^{\circ} 26^{\prime} 49,85^{\prime \prime} \mathrm{N}$ & $42^{\circ}-04^{\prime} 06,13^{\prime \prime} \mathrm{N}$ & $42 \circ 48^{\prime} 25,45^{\prime \prime} \mathrm{N}$ \\
\hline Longitud & $1933^{\prime} 13,72 \mathrm{~W}$ & $0 \circ 43^{\prime} 21,03 \mathrm{~W}$ & $1037^{\prime} 03,09 \mathrm{~W}$ & $1939^{\prime} 00,05 \mathrm{~W}$ \\
\hline Clasificación USCS (Casagrande) & $\mathrm{CL}$ & $\mathrm{CL}$ & $\mathrm{CL}$ & $\mathrm{CL}$ \\
\hline \multicolumn{5}{|l|}{ Proctor normal UNE 103500} \\
\hline Densidad máxima $\left(\mathrm{g} / \mathrm{cm}^{3}\right)$ & 1,70 & 1,68 & 1,76 & 1,97 \\
\hline Humedad óptima (\%) & 19,2 & 16,6 & 15,4 & 12,2 \\
\hline $\begin{array}{l}\text { Hinchamiento libre (\%) } \\
\text { UNE } 103601\end{array}$ & 4,22 & 2,11 & 3,88 & 0,00 \\
\hline $\begin{array}{l}\text { Límites de Atterberg } \\
\text { UNE } 103103 \\
\text { UNE } 103104\end{array}$ & $\begin{array}{l}L L=39 \\
L P=24 \\
P I=15\end{array}$ & $\begin{array}{l}\mathrm{LL}=34 \\
\mathrm{LP}=22 \\
\mathrm{PI}=12\end{array}$ & $\begin{array}{l}\mathrm{LL}=45 \\
\mathrm{LP}=25 \\
\mathrm{PI}=20\end{array}$ & $\begin{array}{l}\mathrm{LL}=26 \\
\mathrm{LP}=18 \\
\mathrm{PI}=8\end{array}$ \\
\hline Análisis de óxidos XRF & \multicolumn{4}{|c|}{ Concentración (\% en masa) } \\
\hline $\mathrm{Na}_{2} \mathrm{O}$ & 0,52 & 0,28 & 0,77 & 0,36 \\
\hline $\mathrm{MgO}$ & 5,22 & 7,08 & 4,15 & 2,06 \\
\hline $\mathrm{Al}_{2} \mathrm{O}_{3}$ & 10,29 & 7,66 & 17,64 & 11,30 \\
\hline $\mathrm{SiO}_{2}$ & 22,87 & 19,25 & 39,05 & 30,78 \\
\hline $\mathrm{P}_{2} \mathrm{O}_{5}$ & 0,17 & 0,08 & 0,18 & 0,12 \\
\hline $\mathrm{SO}_{3}$ & 23,46 & 23,73 & 0,30 & 0,00 \\
\hline $\mathrm{K}_{2} \mathrm{O}$ & 2,38 & 2,00 & 3,556 & 1,96 \\
\hline $\mathrm{CaO}$ & 26,38 & 24,95 & 17,10 & 36,64 \\
\hline $\mathrm{TiO}_{2}$ & 0,37 & 0,34 & 0,64 & 0,53 \\
\hline $\mathrm{Cr}_{2} \mathrm{O}_{3}$ & --- & --- & 0,03 & 0,03 \\
\hline $\mathrm{MnO}$ & 0,03 & 0,04 & 0,09 & 3,43 \\
\hline $\mathrm{Fe}_{2} \mathrm{O}_{3}$ & 3,14 & 2,79 & 5,98 & 0,01 \\
\hline $\mathrm{Rb}_{2} \mathrm{O}$ & 0,01 & 0,01 & 0,01 & 0,13 \\
\hline SrO & 0,15 & 0,41 & 0,02 & 1,96 \\
\hline $\mathrm{ZnO}$ & --- & --- & 0,013 & --- \\
\hline $\mathrm{ZrO}_{2}$ & --- & --- & 0,028 & 0,029 \\
\hline $\mathrm{BaO}$ & --- & 0,0055 & 0,088 & 0,061 \\
\hline $\mathrm{Cl}$ & --- & 0,044 & 0,024 & --- \\
\hline $\mathrm{Y}_{2} \mathrm{O}_{3}$ & --- & 0,002 & 0,004 & 0,001 \\
\hline \multicolumn{5}{|l|}{ Mineralogía XRD } \\
\hline & Cuarzo & Cuarzo & Cuarzo & Calcita \\
\hline & Calcita & Yeso & Calcita & Illita \\
\hline & Yeso & Moscovita & Moscovita & Cuarzo \\
\hline & Moscovita & Caolinita & Dolomita & Caolinita \\
\hline & Caolinita & Dolomita & Clorita & Atapulgita \\
\hline & Dolomita & --- & Yeso & Anquerita \\
\hline & Magnesita & --- & --- & --- \\
\hline Impacto del $\mathrm{CO}_{2}\left(\mathrm{~kg} \mathrm{CO}_{2} / \mathrm{t}\right)$ & --- & --- & --- & 4 \\
\hline Impacto energético (MJ/t ) & --- & --- & --- & 100 \\
\hline
\end{tabular}

Tabla 2. Caracterización de los suelos considerados

Los tipos de residuo utilizados como relleno en este estudio fueron tres: hormigón, escorias de biomasa y ladrillos cocidos. La Tabla 3 muestra la caracterización de los residuos utilizados desde un punto de vista mecánico y un punto de vista químico. 


\begin{tabular}{|c|c|c|c|}
\hline NOMBRE & $\begin{array}{l}\text { HORMIGÓN } \\
\text { RECICLADO }\end{array}$ & $\begin{array}{l}\text { ESCORIA DE } \\
\text { BIOMASA }\end{array}$ & LADRILLOS COCIDOS \\
\hline \multicolumn{4}{|c|}{ Densidad-humedad UNE 103500} \\
\hline Densidad máxima $\left(\mathrm{g} / \mathrm{cm}^{3}\right)$ & 1,90 & --- & --- \\
\hline Humedad óptima (\%) & 15,0 & --- & --- \\
\hline $\begin{array}{l}\text { Hinchamiento libre (\%) } \\
\text { UNE } 103601\end{array}$ & 0,00 & 0,00 & 0,00 \\
\hline $\begin{array}{l}\text { Límites de Atterberg } \\
\text { UNE } 103103 \text { y UNE } 103104\end{array}$ & No plástico & No plástico & No plástico \\
\hline Análisis de óxidos XRF & \multicolumn{3}{|c|}{ Concentración (\% en masa) } \\
\hline $\mathrm{Na}_{2} \mathrm{O}$ & 0,20 & 1,57 & 0,77 \\
\hline $\mathrm{MgO}$ & 1,26 & 1,68 & 4,15 \\
\hline $\mathrm{Al}_{2} \mathrm{O}_{3}$ & 7,07 & 1,39 & 17,64 \\
\hline $\mathrm{SiO}_{2}$ & 20,57 & 27,22 & 39,05 \\
\hline $\mathrm{P}_{2} \mathrm{O}_{5}$ & 0,13 & 2,17 & 0,18 \\
\hline $\mathrm{SO}_{3}$ & 11,36 & 7,51 & 0,30 \\
\hline $\mathrm{K}_{2} \mathrm{O}$ & 0,92 & 24,34 & 3,56 \\
\hline $\mathrm{CaO}$ & 42,23 & 13,03 & 17,10 \\
\hline $\mathrm{TiO}_{2}$ & 0,36 & 0,11 & 0,64 \\
\hline $\mathrm{Cr}_{2} \mathrm{O}_{3}$ & --- & 0,06 & 0,03 \\
\hline $\mathrm{MnO}$ & 0,04 & 0,06 & 0,09 \\
\hline $\mathrm{Fe}_{2} \mathrm{O}_{3}$ & 2,47 & 1,10 & 5,98 \\
\hline $\mathrm{Rb}_{2} \mathrm{O}$ & 0,01 & 0,01 & 0,01 \\
\hline $\mathrm{SrO}$ & 0,11 & 0,10 & 0,02 \\
\hline $\mathrm{ZnO}$ & 0,02 & 0,015 & 0,013 \\
\hline $\mathrm{ZrO}_{2}$ & 0,02 & 0,017 & 0,03 \\
\hline $\mathrm{BaO}$ & 0,06 & 0,081 & 0,09 \\
\hline $\mathrm{Cl}$ & 0,03 & 7,487 & 0,02 \\
\hline \multirow[t]{6}{*}{ Mineralogía XRD } & Caolinita & Cuarzo & Cuarzo \\
\hline & Calcita & Silvita & Calcita \\
\hline & Cuarzo & Arcanita & Moscovita \\
\hline & Yeso & --- & Dolomita \\
\hline & Moscovita & --- & Clorita \\
\hline & --- & --- & Yeso \\
\hline
\end{tabular}

Tabla 3. Caracterización de los residuos para relleno considerados

Para el primero de los artículos de la Tesis (de estabilización de suelos con presencia de sulfatos), el hormigón reciclado proviene de la fracción de menos de $5 \mathrm{~mm}$, obtenida de la trituración de estructuras viejas de hormigón de una obra en Pamplona (España). Este material reciclado contiene un $5 \%$ de sulfato, principalmente debido a que los restos de yeso desmenuzados en el hormigón. Para el tercero de los artículos de la Tesis (de fabricación con residuos de ladrillos no cocidos), se emplea la fracción fina de hormigones procedentes de la trituración de hormigones estructurales, suministrada por una planta de reciclaje en Vitoria, también en el norte de España. La planta de reciclaje sólo valoriza la fracción de 40-100 mm como RA, mientras que las partículas más finas se eliminan en un vertedero. Para esta 
investigación, se preparó una muestra que pesaba 100 kg y con un tamaño de partícula máximo de $4 \mathrm{~mm}$ tamizando la fracción de 0-40 $\mathrm{mm}$.

Las escorias de biomasa, empleadas para generar un suelo de diseño para el artículo sobre estabilización de suelos con sulfatos, procedieron de una planta navarra de producción de electricidad a partir de la combustión de paja de cereal.

En el caso de los ladrillos cocidos reciclados se empleó -para la investigación publicada en el artículo, incluido en el cuerpo de esta Tesis, sobre valorización de CDW- la fracción fina de este material cerámico (tamaño inferior a $4 \mathrm{~mm}$ ). Y, se obtuvo también de la misma planta de reciclaje en Vitoria que el hormigón empleado en el mismo artículo. En el caso de estos ladrillos reciclados, para evitar la contaminación del CDW por componentes tales como yeso, mortero, etc., se seleccionaron ladrillos de tamaño completo, se trituraron, y se tamizó el resultado para obtener el tamaño requerido.

En el caso de la arena, para el segundo artículo de este estudio (de estimación de la durabilidad de los ladrillos no cocidos), se utilizó arena comercial de silicio para morteros. Esta arena se obtuvo de la trituración de rocas silíceas naturales. Para el cuarto artículo incluido en la Tesis -sobre fabricación de muestras de mortero- se utilizó una arena calcárea, obtenida de trituración de roca caliza, de granulometría comercial de $0 / 2 \mathrm{~mm}$, de acuerdo con la norma europea EN 13139 "Áridos para morteros" (CEN, 2002, 2004).

\section{Materiales activos}

Los materiales intencionadamente activos empleados se pueden clasificar en dos categorías principales: ligantes/precursores y activadores alcalinos empleados. El tipo de material, y la evidencia (artículo) en el que se emplean, se indican en la Tabla 4.

\begin{tabular}{|l|c|c|}
\hline ADITIVO & TIPO DE MATERIAL & EVIDENCIA \\
\hline GGBS & Subproducto & $1,2,3,4$ \\
\hline PC-8 & Subproducto & 1,2 \\
\hline CL-90-S (cal hidratada calcárea) & Producto & $1,2,3$ \\
\hline NHL-5 (cal hidratada natural) & Producto & 2 \\
\hline Cemento Portland CEM I 52,5 N & Producto & $2,3,4$ \\
\hline Cemento CEM IIII/A 42,5 N & Producto & 4 \\
\hline Cemento CEM IIII/B 32,5 N & Producto & 4 \\
\hline Cemento CEM IV/B 32,5 N & Producto & 4 \\
\hline Cemento CEM V/A 32,5 N & Producto & 4 \\
\hline FA & Residuo & 4 \\
\hline NaOH & Producto & 4 \\
\hline Silicato de sodio & Producto & 4 \\
\hline
\end{tabular}

Tabla 4. Materiales intencionadamente activos empleados 
Los activadores alcalinos consistieron en soluciones 6, 8 y $10 \mathrm{M}$ de escamas de $\mathrm{NaOH}$ puro mezcladas con silicato de sodio $\left(\mathrm{Na}_{2} \mathrm{O} \bullet 3.3 \mathrm{SiO}_{3}\right)$.

La Tabla 5 muestra la composición de los ligantes y precursores considerados en este trabajo, excluidos los cementos, expresada en forma de sus óxidos más importantes, basado en análisis por XRF. La Tabla 5 también muestra el $\mathrm{CO}_{2}$ producido y la energía consumida en el proceso de producción de estos ligantes, como se define por Grist et al. (2015).

\begin{tabular}{|c|c|c|c|c|c|}
\hline Óxidos (\%) & PC-8 & CL-90-S & NHL-5 & GGBS & FA \\
\hline $\mathrm{SiO}_{2}$ & 3,41 & --- & 12 & $35-38$ & 49,1 \\
\hline $\mathrm{CaO}$ & 7 & --- & --- & $37-42$ & 3,9 \\
\hline $\mathrm{Ca}(\mathrm{OH})_{2}$ & & $>95$ & 53 & --- & --- \\
\hline $\mathrm{Fe}_{2} \mathrm{O}_{3}$ & 2,42 & --- & & $0,35-0,5$ & --- \\
\hline $\mathrm{Al}_{2} \mathrm{O}_{3}$ & 0,56 & --- & 10 & 11,6 & 18,4 \\
\hline $\mathrm{SO}_{3}$ & $5-8$ & --- & & 0,23 & --- \\
\hline MgO & 61,85 & --- & & $8-10$ & 1,5 \\
\hline $\mathrm{Fe}_{2} \mathrm{O}_{3}, \mathrm{SO}_{3}$ y otros & --- & --- & & 3 & 27,1 \\
\hline $\begin{array}{l}\text { Impacto del } \mathrm{CO}_{2} \\
\left(\mathrm{~kg} \mathrm{CO}_{2} / \mathrm{t}\right)\end{array}$ & --- & 760 & 635 & $52-126$ & 9,51 \\
\hline $\begin{array}{l}\text { Impacto energético } \\
\text { (MJ/t) }\end{array}$ & --- & 3256 & 2721 & 1300 & --- \\
\hline Suministrador & $\begin{array}{c}\text { Magnesitas } \\
\text { de Navarra } \\
\text { S.A. }\end{array}$ & --- & --- & $\begin{array}{c}\text { Hanson } \\
\text { Heidelberg } \\
\text { Cement } \\
\text { Group }\end{array}$ & $\begin{array}{l}\text { Cementos } \\
\text { Tudela } \\
\text { Veguín } \\
\text { S.A. }\end{array}$ \\
\hline País de origen & España & --- & --- & $\begin{array}{l}\text { Reino } \\
\text { Unido }\end{array}$ & España \\
\hline
\end{tabular}

Tabla 5. Excluidos los cementos: Riqueza/composición en óxidos de los ligantes y precursores empleados (\% en masa) y de la producción de $\mathrm{CO} 2$ y consumo de energía de los ligantes empleados

Las GGBS son un subproducto obtenido durante la producción de acero en alto horno, que se forma mediante la combinación de mineral de hierro con fundente de piedra caliza (castina). Se enfría rápidamente, se produce poca o ninguna cristalización y que muestra un estado vítreo. Este proceso da como resultado la formación de fragmentos de tamaño de arena, generalmente con algún material friable similar al clínker. Finamente molido, este material muestra una reactividad importante basada en su riqueza en óxidos de calcio, aluminio y silicio.

El PC-8 es un subproducto rico en MgO, obtenido durante la producción de magnesita mediante la calcinación de $\mathrm{MgCO}_{3}$ a $1100 \stackrel{\circ}{\circ}$. Este proceso se lleva a cabo en un horno rotatorio con circulación de aire a contracorriente, que extrae partículas de polvo a lo largo de todo el horno. De modo que, este polvo, que se recupera mediante ciclones de aire, contiene $\mathrm{MgCO}_{3}$ 
(inerte), MgO calcinado (reactivo) y partículas vitrificadas de $\mathrm{MgO}$ (inertes). La muestra utilizada en este estudio fue suministrada por la compañía Magnesitas de Navarra S.A.

En este estudio se utilizaron dos cales (materiales ricos en $\mathrm{Ca}(\mathrm{OH})_{2}$ ) de diferente tipo. Una cal hidráulica natural (NHL-5), obtenida de caliza no pura quemada y fabricada de acuerdo con la norma europea EN 459-1 (CEN, 2016). Esta cal tiene propiedades hidráulicas debido a la presencia de óxidos de aluminio y silicio, así como calcio libre en forma de óxido de calcio. Y, también se utilizó en el estudio una cal hidratada calcárea (CL-90-S), obtenida de caliza pura quemada y fabricada, como la anterior, de acuerdo con la norma europea EN 459-1 (CEN, 2016).

Las FA son un residuo de polvo fino que resulta de la combustión de carbón en las centrales generadoras de energía eléctrica. En este estudio, se utilizaron FA clasificadas como clase $F$ de acuerdo con la norma ASTM C618 (ASTM, 2017) para la fabricación de AAB. La muestra de FA utilizada fue suministrada por Cementos Tudela Veguín S.A.

Los cementos utilizados en este estudio se comercializan bajo los nombres comerciales CEM I $52.5 \mathrm{~N}$, CEM III/A 42,5 N CEM III/B 32,5 N, CEM IV/B 32,5 N y CEM V/A 32,5 N. Estos cementos se fabricaron de acuerdo con la norma europea EN 197-1 (CEN, 2011a). Esta Norma considera, en función de su composición, cinco grupos (I-V) de cementos comunes. La designación del cemento contiene su tipo, seguido de su resistencia mecánica a los 28 días. Así, CEM I $52.5 \mathrm{~N}$ es un cemento común -el único de los utilizados que es tipo Portland- hecho principalmente de clinker (tipo I), que obtuvo $52.5 \mathrm{MPa}$ en el ensayo compresión. Además del CEM I $52.5 \mathrm{~N}$, como se ha indicado, se consideraron otros cuatro cementos comerciales comunes, que contienen diferentes porcentajes de clinker, caliza, FA, GGBS y yeso. La Tabla 6 muestra la composición de los cementos hidráulicos considerados, así como su resistencia a compresión.

\begin{tabular}{|c|c|c|c|c|c|c|}
\hline CEMENTO & $\begin{array}{c}\text { RESISTENCIA } \\
\text { A } \\
\text { COMPRESIÓN } \\
\text { (MPA) }\end{array}$ & \multicolumn{5}{|c|}{ COMPONENTES (\%) } \\
\hline & & Clinker & Piedra caliza & FA & GGBS & Yeso \\
\hline CEM I 52,5 & 52,5 & 95 & 2 & & & 3 \\
\hline $\begin{array}{c}\text { CEM III/A } \\
42,5\end{array}$ & 42,5 & 54 & & & 41 & 5 \\
\hline $\begin{array}{c}\text { CEM III/B } \\
32,5\end{array}$ & 32,5 & 25 & & & 70 & 5 \\
\hline $\begin{array}{c}\text { CEM IV/B } \\
32,5\end{array}$ & 32,5 & 49 & & 27 & 28 & 5 \\
\hline $\begin{array}{c}\text { CEM V/A } \\
32,5\end{array}$ & 32,5 & 40 & & & & 2 \\
\hline
\end{tabular}

Tabla 6. Composición (\% en peso) de los cementos comunes considerados

La Tabla 7 muestra la composición química de las muestras de cemento, expresadas como óxidos, obtenidas por Fluorescencia de Rayos X (XRF). 


\begin{tabular}{|l|c|c|c|c|c|}
\hline Óxidos & $\begin{array}{c}\text { Portland CEM } \\
\mathbf{I} \mathbf{5 2 . 5} \mathbf{~ N}\end{array}$ & $\begin{array}{c}\text { CEM III/A } \\
\mathbf{4 2 , 5} \mathbf{~ N}\end{array}$ & $\begin{array}{c}\text { CEM III/B } \\
\mathbf{3 2 , 5} \mathbf{~ N}\end{array}$ & $\begin{array}{c}\text { CEM IV/B } \\
\mathbf{3 2 , 5} \mathbf{~ N}\end{array}$ & $\begin{array}{c}\text { CEM V/A } \\
\mathbf{3 2 , 5} \mathbf{~ N}\end{array}$ \\
\hline $\mathrm{SiO}_{2}$ & $19-25$ & 26,8 & 30,7 & 31,7 & 34,7 \\
\hline $\mathrm{CaO}$ & $63-65$ & 53 & 47,4 & 37,5 & 39,6 \\
\hline $\mathrm{Fe}_{2} \mathrm{O}_{3}$ & 0,5 & --- & --- & --- & --- \\
\hline $\mathrm{Al}_{2} \mathrm{O}_{3}$ & $3-6$ & 7,8 & 9,5 & 12,9 & 11,2 \\
\hline $\mathrm{SO}_{3}$ & 4 & --- & --- & --- & --- \\
\hline $\mathrm{MgO}$ & $1-2$ & 4,3 & 5,2 & 2,0 & 3,3 \\
\hline $\mathrm{Fe}_{2} \mathrm{O}_{3}, \mathrm{SO}_{3}$ y otros & 9,3 & 8,1 & 7,2 & 15,9 & 11,2 \\
\hline Impacto energético $(\mathrm{MJ} / \mathrm{t})$ & 3800 & --- & --- & --- & --- \\
\hline $\begin{array}{l}\text { Impacto del } \mathrm{CO} \\
\text { de los morteros }\end{array}$ & 219 & 144 & 91,2 & 113 & 111 \\
\hline
\end{tabular}

Tabla 7. Caracterización de la riqueza química de los cementos expresada en \% en peso de sus óxidos principales

\subsubsection{Métodos}

\section{Dosificación de las muestras}

Para cada uno de los cuatro artículos incluidos en el Cuerpo de la Tesis se hizo un estudio particular de las dosificaciones de las muestras a ensayar.

Para el primero de ellos, de estabilización de suelos con presencia de sulfatos (ver capítulo 3. Cuerpo), además de tres suelos naturales con sulfatos (I, II y III) y un cuarto formado por la fracción fina de residuos de hormigón (IV), se quiso probar el efecto sobre otro suelo artificial, identificado como $\mathrm{V}$, formado por la mezcla de un suelo de marga con residuos (escorias de una planta de generación eléctrica por quema de paja). Para conseguir unas condiciones de trabajabilidad adecuada en los ensayos, la mezcla, para fabricar este suelo $\mathrm{V}$, se hizo en una proporción de $70 \%$ escoria con $30 \%$ de marga. La dosis de los ligantes a relleno para los cinco suelos, se estableció en base a bibliografía (Oti et al., 2008; Seco et al., 2011a y 2011b): Para el ensayo de hinchamiento los cinco suelos se probaron con un $8 \%$ de cal, y con un $8 \%$ de PC- 8 , frente a un $92 \%$ de suelo. Para el resto de los ensayos (ver Tabla 8), los suelos identificados como I, II, III, fueron tratados con PC-8 al 4 y $8 \%$, cal (CL-90-S) al 4 y $8 \%$, PC-8 al $2 \%$ más GGBS al $8 \%$ y cal al $2 \%$ más GGBS al $8 \%$. En el caso de los suelos IV y V, las combinaciones de PC-8 y cal solos, debido a la falta de minerales de arcilla en el hormigón triturado y en las escorias de biomasa, no se emplearon las combinaciones con PC-8 o cal sin GGBS. 


\begin{tabular}{|c|c|c|c|c|c|}
\hline COMBINACIÓN & PC-8 & CL-90-S & GGBS & SUELOS I, II O III & SUELOS IV O V \\
\hline 1 & 4 & & & 96 & \\
\hline 2 & 8 & & & 92 & \\
\hline 3 & & 4 & & 96 & \\
\hline 4 & & 8 & & 92 & \\
\hline 5 & 2 & & 8 & 90 & \\
\hline 6 & 2 & & 8 & 90 & 90 \\
\hline 7 & 2 & & 8 & & 90 \\
\hline 8 & 2 & & 8 & & \\
\hline
\end{tabular}

Tabla 8. Composición de las combinaciones con suelos con sulfatos sometidas a ensayos mecánicos (\% en peso) en la primera evidencia (estabilización)

En el segundo de los artículos, sobre ensayos de laboratorio para estimar la durabilidad de ladrillos no cocidos, las combinaciones de mezcla contenían un $10 \%$ de ligante y un $90 \%$ de material de relleno, en el que se incluyeron porcentajes variables de arena. La Tabla 9 muestra las diferentes mezclas estudiadas.

\begin{tabular}{|c|c|c|c|}
\hline \multirow{2}{*}{ COMBINACIÓN } & \multirow{2}{*}{ LIGANTE (10\%) } & \multicolumn{2}{|c|}{ RELLENO } \\
\cline { 3 - 4 } & & Marga (\%) & Arena (\%) \\
\hline 1 & Cemento Portland & 90 & 0 \\
\hline 2 & Cemento Portland & 80 & 10 \\
\hline 3 & Cemento Portland & 60 & 30 \\
\hline 4 & Cemento Portland & 40 & 50 \\
\hline 5 & Cal hidráulica & 90 & 0 \\
\hline 6 & Cal hidráulica & 80 & 10 \\
\hline 7 & Cal hidráulica & 60 & 30 \\
\hline 8 & Cal hidráulica & 40 & 50 \\
\hline 9 & CL-90-S+GGBS & 90 & 0 \\
\hline 10 & CL-90-S+GGBS & 80 & 10 \\
\hline 11 & CL-90-S+GGBS & 60 & 30 \\
\hline 12 & CL-90-S+GGBS & 40 & 50 \\
\hline 13 & PC-8+GGBS & 90 & 0 \\
\hline 14 & PC-8+GGBS & 80 & 10 \\
\hline 15 & PC-8+GGBS & 60 & 30 \\
\hline 16 & PC-8+GGBS & 40 & 50 \\
\hline
\end{tabular}

Tabla 9. Combinaciones ensayadas en la segunda evidencia (durabilidad) 
En este segundo artículo, las GGBS se utilizaron combinadas con la cal hidratada o el PC-8 como activadores con una relación de $20 \%$ de CL-90-S o $20 \%$ de PC- 8 con $80 \%$ de GGBS con ambos materiales.

Para la tercera evidencia incluida en el cuerpo de la Tesis, que trata sobre la fabricación de ladrillos no cocidos con residuos de hormigón y ladrillo cerámico, antes de la producción de las muestras, en función de los requisitos de trabajabilidad según la Norma UNE 41410 (AENOR, 2008), se determinó la relación máxima posible de sustitución del suelo de marga para cada tipo de CDW. Para la fracción fina de hormigón, se determinó que la tasa de sustitución máxima era del $50 \%$ del suelo, mientras que para los residuos cerámicos era del $30 \%$. Una vez que se definieron las tasas de sustitución para cada tipo de residuo, los especímenes de laboratorio se prepararon, de acuerdo con el método descrito por Seco et al. (2017), de suelo sin residuos y con esas tasas de sustitución. Los especímenes de suelo puro, que se utilizaron para obtener un valor de referencia de la resistencia a compresión, sólo se combinaron con un $10 \%$ de PC $(90 \%$ suelo natural de marga).

La Tabla 10 muestra las combinaciones de dosificación de ligantes, expresadas como porcentaje de ligante sobre peso total de ladrillo.

\begin{tabular}{|c|c|c|c|c|c|}
\hline COMBINACIÓN & LIGANTE & PC (\%) & CL-90-S (\%) & NHL-5 (\%) & GGBS (\%) \\
\hline 1 & PC & 4 & & & \\
\hline 2 & & 6 & & & \\
\hline 3 & & 8 & & & \\
\hline 4 & & 10 & & & \\
\hline 5 & CL-90-S & & 4 & & \\
\hline 6 & & & 6 & & \\
\hline 7 & & & 8 & & \\
\hline 8 & & & 10 & & \\
\hline 9 & NHL-5 & & & 4 & \\
\hline 10 & & & & 6 & \\
\hline 11 & & & & 8 & \\
\hline 12 & & & & 10 & \\
\hline 13 & CL-90-S+ PC & 8 & 2 & & \\
\hline 14 & & 6 & 4 & & \\
\hline 15 & & 4 & 6 & & \\
\hline 16 & & 2 & 8 & & \\
\hline 17 & CL-90-S+ GGBS & & 2 & & 8 \\
\hline 18 & & & 4 & & 6 \\
\hline 19 & & & 6 & & 4 \\
\hline 20 & & & 8 & & 2 \\
\hline
\end{tabular}

Tabla 10. Proporciones ensayadas de ligantes en la tercera evidencia (CDW) 
Para el cuarto artículo incluido en el cuerpo de esta Tesis, de comparación desde el punto de vista ambiental de la sustitución en los morteros del cemento Portland CEM I por otros ligantes hidráulicos y por $A A B$, se determinó por un lado la proporción entre la disolución de $\mathrm{NaOH}$ y el silicato de calcio, por otro lado de precursor/activador de los activadores alcalinos; $y$ la dosificación relleno/ligante de los morteros por otro.

La proporción relleno/ligante fue 2/1.

Para el precursor, que contiene $\mathrm{NaOH}$ y silicato de sodio, se fijó, basada en FernándezJiménez et al. (2006) y otros, la proporción disolución en agua $(6,8$ y $10 \mathrm{M}) \mathrm{de} \mathrm{NaOH}$ a silicato de 7:3. Las soluciones de $\mathrm{NaOH}$ se prepararon mediante la disolución en agua. Para evitar el efecto del calor liberado durante la preparación de la solución, sobre la cinética de activación de los $A A B$, las soluciones se prepararon y se guardaron en contenedores cerrados a temperatura ambiente en el laboratorio durante $24 \mathrm{~h}$, antes de su uso.

La proporción precursor/activador se mantuvo en una proporción constante de 7/3 basada en Shi et al. (2005) y Yang et al. (2012) entre otros.

La Tabla 11 muestra las combinaciones de mortero (1 a 20), cinco de cementos hidráulicos y quince a base de $A A B$, consideradas para la investigación de laboratorio llevada a cabo. La cantidad de agua (no incluida en la Tabla 11) a añadir al relleno+ligante, para conseguir una trabajabilidad adecuada, varió en cada caso dependiendo del ensayo de consistencia. 


\begin{tabular}{|c|c|c|c|c|c|c|}
\hline \multirow{5}{*}{\multicolumn{2}{|c|}{$\begin{array}{l}\text { CÓDIGO DE LA } \\
\text { MUESTRA }\end{array}$}} & RELLENO & \multicolumn{4}{|c|}{ LIGANTES } \\
\hline & & \multirow[t]{4}{*}{$66,7 \%$} & \multicolumn{4}{|c|}{$33,3 \%$} \\
\hline & & & \multirow{3}{*}{$\begin{array}{c}\begin{array}{c}\text { Ligantes } \\
\text { hidráulicos }\end{array} \\
\begin{array}{c}100 \% \\
\text { Cemento } \\
\text { (\% en peso) }\end{array}\end{array}$} & \multicolumn{3}{|c|}{ Ligantes alcalinos } \\
\hline & & & & \multicolumn{2}{|c|}{$\begin{array}{c}70 \% \text { de precursor } \\
\text { (\% en peso) }\end{array}$} & \multirow{2}{*}{$\begin{array}{c}\begin{array}{c}30 \% \text { de Activador } \\
\text { (\% en peso) }\end{array} \\
\begin{array}{c}\text { Molaridad del } \\
\mathrm{NaOH}\end{array}\end{array}$} \\
\hline & & & & $\begin{array}{l}\text { GGBS (\% } \\
\text { en peso) }\end{array}$ & $\begin{array}{l}\text { FA ( } \% \text { en } \\
\text { peso) }\end{array}$ & \\
\hline 1 & CEM I 52,5 & Arena & CEM I 52,5 & & & \\
\hline 2 & CEM III/A 42,5 & Arena & CEM III/A 42,5 & & & \\
\hline 3 & CEM III/B 32,5 & Arena & CEM III/B 32,5 & & & \\
\hline 4 & CEM IV/B 32,5 & Arena & CEM IV/B 32,5 & & & \\
\hline 5 & CEM V/A 32,5 & Arena & CEM V/A 32,5 & & & \\
\hline 6 & GGBS 6M & Arena & & 100 & & 6 \\
\hline 7 & $\begin{array}{c}\text { GGBS 75:25 FA } \\
6 \mathrm{M}\end{array}$ & Arena & & 75 & 25 & 6 \\
\hline 8 & $\begin{array}{c}\text { GGBS 50:50 FA } \\
6 \mathrm{M}\end{array}$ & Arena & & 50 & 50 & 6 \\
\hline 9 & $\begin{array}{c}\text { GGBS 25:75 FA } \\
6 \mathrm{M}\end{array}$ & Arena & & 25 & 75 & 6 \\
\hline 10 & FA 6M & Arena & & & 100 & 6 \\
\hline 11 & GGBS 8M & Arena & & 100 & & 8 \\
\hline 12 & $\begin{array}{c}\text { GGBS 75:25 FA } \\
8 \mathrm{M}\end{array}$ & Arena & & 75 & 25 & 8 \\
\hline 13 & $\begin{array}{c}\text { GGBS 50:50 FA } \\
8 \mathrm{M}\end{array}$ & Arena & & 50 & 50 & 8 \\
\hline 14 & $\begin{array}{c}\text { GGBS 25:75 FA } \\
8 \mathrm{M}\end{array}$ & Arena & & 25 & 75 & 8 \\
\hline 15 & FA 8M & Arena & & & 100 & 8 \\
\hline 16 & GGBS 10M & Arena & & 100 & & 10 \\
\hline 17 & $\begin{array}{c}\text { GGBS } 75: 25 \mathrm{FA} \\
10 \mathrm{M}\end{array}$ & Arena & & 75 & 25 & 10 \\
\hline 18 & $\begin{array}{c}\text { GGBS 50:50 FA } \\
10 \mathrm{M}\end{array}$ & Arena & & 50 & 50 & 10 \\
\hline 19 & $\begin{array}{c}\text { GGBS } 25: 75 \mathrm{FA} \\
10 \mathrm{M}\end{array}$ & Arena & & 25 & 75 & 10 \\
\hline 20 & FA 10M & Arena & & & 100 & 10 \\
\hline
\end{tabular}

Tabla 11. Mezclas ensayadas en la investigación del cuarto artículo (\% en peso) (morteros) 


\section{Preparación de muestras}

En el caso de los suelos, el único pretratamiento realizado consistió en triturarlos y tamizarlos para obtener partículas de tamaños inferiores a $2 \mathrm{~mm}$ (estabilización) o $1 \mathrm{~mm}$ (CDW), para permitir un mejor contacto suelo-aditivo. La muestra se caracterizó determinando sus límites de Atterberg siguiendo las normas 103103 (AENOR, 1994a) y UNE 103104 (AENOR, 1993a).

Se prepararon cuatro tipos de muestras durante la fase experimental de la investigación:

El primer tipo, lo formaron las muestras destinas a establecer las propiedades mecánicas de las combinaciones probadas. Para cada combinación suelo, suelo/arena, se estableció el contenido de humedad óptimo (OMC) correspondiente a la energía de compactación, de acuerdo con el procedimiento definido en la norma española UNE 103500 (AENOR, 1994b). Después de eso, las mezclas de tierra, arena y aditivos se llevaron a cabo en una mezcladora industrial hasta su homogeneización completa y, luego, se agregó agua lentamente para obtener su distribución uniforme. Después de un tiempo, la mezcla húmeda, se trató en un homogeneizador de alta velocidad para garantizar la adecuada distribución de humedad. Una vez que se verificó visualmente la calidad de las mezclas, se prepararon muestras cilíndricas de $65 \mathrm{~mm}$ de diámetro y $75 \mathrm{~mm}$ de altura, presionando el material en un molde a una presión de 8-9 MPa. Las muestras se desmoldaron inmediatamente después de la fabricación y el tiempo de curado, desde la fabricación hasta la edad de ensayo, para mantener la humedad, los especímenes se cubrieron con láminas de polietileno, y se mantuvieron en una cámara húmeda a $20^{\circ} \mathrm{C}$ y $100 \%$ de humedad relativa (HR).

El segundo tipo, para establecer la estabilidad a largo plazo de los suelos tratados contra el ataque por sulfatos. Para este fin, se prepararon muestras de $50 \mathrm{~mm}$ de diámetro y $2 \mathrm{~mm}$ de altura, dentro de los anillos del edómetro, con la densidad máxima de y el contenido de humedad óptimo de la muestra, para las combinaciones con $8 \%$ de aditivos basados en calcio y magnesio. En estos casos, dado que las cantidades de material eran pequeñas (aproximadamente $200 \mathrm{~g}$ en cada caso), tanto la mezcla como los procedimientos de compactación se realizaron manualmente de acuerdo con la norma española UNE 103601 (AENOR, 1996).

El tercer tipo, para el ensayo heladicidad de los ladrillos que incluían residuos de hormigón o ladrillo. Para ello, por el mismo procedimiento que las de la primera categoría, se prepararon muestras prismáticas de 225×110x60 mm.

En el cuarto, para la fabricación de morteros, todas las probetas, tanto las que utilizaron ligantes hidráulicos como las alcalinas, se hicieron de 50×50×50 mm. En las basadas en ligantes hidráulicos, el cemento y la arena se mezclaron previamente en un mezclador de mortero de laboratorio durante 10 minutos. Después de esta mezcla en seco, se añadió cuidadosamente la cantidad requerida de agua para alcanzar las condiciones de consistencia que se definieron previamente. La mezcla húmeda se mantuvo durante $10 \mathrm{~min}$ para garantizar la homogeneización de la muestra de mortero. Para las muestras de mortero activado alcalinamente, después de mezclar previamente por separado los líquidos y los sólidos entre sí, 
se juntaron ambas fases en un mezclador de mortero de laboratorio hasta su completa homogeneización. Las muestras frescas activadas hidráulicamente y alcalinamente se vertieron en moldes de acero de y se hicieron vibrar durante 5 minutos en una mesa vibratoria para eliminar cualquier burbuja de aire posible, así como para el correcto llenado de los moldes. A los alcalinos se les tuvo además 24 horas a temperatura ambiente recubiertos con un film plástico. Tras esto, todos los morteros se curaron en cámara húmeda a $20^{\circ} \mathrm{C}$ y $100 \%$ de HR hasta las edades de ensayo.

\section{Ensayos y análisis}

Los ensayos y análisis principales realizados para realizar los artículos que se incluyen en el cuerpo de la Tesis se pueden agrupar en las siguientes categorías:

1. Ensayos iniciales.

2. Propiedades mecánicas (resistencia a compresión).

3. Estabilidad a largo plazo.

4. Humectación/secado y erosión acelerada

5. Absorción de agua

6. Heladicidad

7. Durabilidad

8. Determinación de tiempos de fraguado

9. Análisis de Ciclo de Vida (LCA)

Todos los ensayos de laboratorio se llevaron a cabo siguiendo, o inspirándose en, procedimientos indicados en normas españolas e internacionales.

Inicialmente, para todos los trabajos incluidos en esta Tesis se determinó, mediante análisis por XRF, la composición de los materiales expresada como sus óxidos más significativos; Y, además, salvo en estudio de los morteros, mediante el análisis por difracción de rayos X (XRD) basado en la carta de interpretación de Al Rawas (1999), sus composiciones mineralógicas.

La caracterización de las propiedades mecánicas de las muestras evaluadas, de acuerdo con el ensayo de rotura a compresión simple definido en la norma española UNE 103400 (AENOR, 1993b), se realizó a diferentes edades. Hasta las edades de ensayo las muestras se mantuvieron en cámara húmeda a $20^{\circ} \mathrm{C}$ y $100 \%$ de HR. Para el caso de los ladrillos basados en EBCM, para estudiar su durabilidad las muestras se han ensayado sólo a 28 días; los de los morteros a 7, 14, 21 y 28 días; los de ladrillos en los que se valorizaban CDW hasta las edades de ensayo de 1, 7, 14, 21 y 28 días; y para el artículo de la estabilización de suelos 1, 7, 14, 21 , 28, 56 y 90 días. La resistencia mecánica de los morteros curados se caracterizó por medio del ensayo a compresión simple (CS), llevado a cabo de acuerdo con el procedimiento definido en la Norma Europea EN 1015-11 (CEN, 2000a, 2007a). Después del curado, para el caso de las muestras de ladrillos fabricados con CDW, las muestras se ensayaron para determinar la resistencia a compresión simple (UCS) de acuerdo con la norma española UNE 103400 (AENOR, 1993b), antes y después de las 24 horas de su inmersión en agua.

La estabilidad a largo plazo, estudiada en el caso estabilización de suelos con sulfatos, se analizó de dos maneras. Por un lado, la estabilidad dimensional de las muestras frente al hinchamiento a largo plazo se determinó mediante edómetro según la norma española UNE 
103601 (AENOR, 1996). Por otro lado, todas las muestras, después de la prueba de hinchamiento, se analizaron por XRD para identificar cualquier posible cambio mineralógico en la composición de las muestras, especialmente el desarrollo de minerales expansivos.

Los ensayos de humectación y el secado y de erosión acelerada de Swinburne, realizadas para el estudio de la durabilidad de los ladrillos fabricados empleando EBCM, se hicieron de acuerdo con la norma española UNE 41410 (AENOR, 2008).

Las pruebas de absorción capilar de agua y absorción de agua (WA), realizadas para el estudio de ladrillos fabricados empleando CDW y, el también aplicado a ladrillos, de la durabilidad de EBCM , se llevaron a cabo siguiendo la normas europeas EN 772-11 (CEN, 2011b) y EN 772-21 (CEN, 2011c).

La resistencia al ciclado hielo-deshielo (ensayo de heladicidad), para el estudio de la durabilidad y de valorización de residuos de ladrillos no cocidos, se estableció aplicando la norma española UNE 67028 EX (AENOR, 1997).

En el caso del estudio de durabilidad de ladrillos no cocidos (ECBM), se colocaron en el exterior y se expusieron a la intemperie muestras de todas las combinaciones, con y $\sin$ tratamiento impermeabilizante, realizándose una inspección visual mensual de los daños observados en las muestras durante 18 meses.

Para la caracterización de morteros frescos, se consideraron los ensayos de tiempo de fraguado y de consistencia en fresco, de acuerdo con las normas europeas EN 480-2 y EN 1015-3 (CEN, 2000b, 2007b), respectivamente.

Con el fin de cuantificar el impacto ambiental de cada mezcla, se llevó a cabo una evaluación del impacto del ciclo de vida (LCIA) basada la Norma ISO 14044 (ISO, 2006) de LCA. La unidad funcional elegida fue una tonelada de material producido (ladrillo o mortero) y los límites del análisis fueron "desde la cuna hasta la puerta" ("from the cadle to the gate"), siguiendo el enfoque de Marcelino-Sadaba et al. (2017). En el caso de los ladrillos, los impactos evaluados incluyen las emisiones de $\mathrm{CO}_{2}$ y la energía incorporada, que se analizaron siguiendo la metodología de Grist et al. (2015). En el caso de los morteros, basados en la legislación de la UE (UE, 2008), las GGBS y FA se consideraron subproductos; de modo que se asignó una emisión proporcional a ambos materiales (Chen et al., 2010; Gala et al., 2015). De acuerdo con Heijungs et al. (1992a y 1992b), los impactos ambientales evaluados incluyeron las categorías de Cambio Climático, Acidificación, Eutrofización y Emisión de particulas expresadas respectivamente como emisiones de $\mathrm{CO}_{2}, \mathrm{PO}_{4}, \mathrm{SO}_{2}$ y particulas equivalentes. Los datos del inventario de emisiones se obtuvieron de Althaus et al. (2007); CEMBUREAU (2016); Dunlap (2003); Habert y Roussel (2009); Kellenberger y Althaus (2009); Turner y Collins (2013); y SimaPro databases 4.0. 


\section{CUERPO}

El cuerpo de este trabajo está formado por los cuatro artículos siguientes:

1. Seco, A., Miqueleiz, L., Prieto, E., Marcelino, S., Garcia, B., Urmeneta, P. (2017). Sulfate soils stabilization with magnesium-based binders. Applied Clay Science. http://doi.org/10.1016/j.clay.2016.10.033. Publicado en el volumen 135 de enero de 2017 de Applied Clay Science: 68 de 285. JCR Q1 en Materials science, Multidisciplinary. Con 4 citas indexadas hasta agosto de 2018.

2. Seco, A., Urmeneta, P., Prieto, E., Marcelino, S., García, B., y Miqueleiz, L. (2017). Estimated and real durability of unfired clay bricks: Determining factors and representativeness of the laboratory tests. Construction and Building Materials, 131, 600-605. http://doi.org/10.1016/J.CONBUILDMAT.2016.11.107. Publicado en el volumen 131 de enero de 2017 de Construction and Building Materials: 11 de 128. JCR Q1 en 2017 en Engineering, Civil. Con 2 citas indexadas hasta agosto de 2018.

3. Seco, A., Omer, J., Marcelino, S., Espuelas, S., y Prieto, E. (2018). Sustainable unfired bricks manufacturing from construction and demolition wastes. Construction and Building Materials, 167. http://doi.org/10.1016/j.conbuildmat.2018.02.026. Publicado en el volumen 167 de abril de 2018 de Construction and Building Materials: 11 de 128. JCR Q1 en 2017 en Engineering, Civil. Sin citas hasta agosto de 2018.

4. Espuelas, S., Echeverria, A. M., Marcelino, S., Prieto, E., y Seco, A. (2018). Technical and environmental characterization of hydraulic and alkaline binders. Journal of Cleaner Production, 196, 1306-1313.

http://doi.org/10.1016/j.jclepro.2018.06.090. Publicado en el volumen 196 de septiembre de 2018 de Journal of Cleaner Production: 21 de 241. JCR Q1 en 2017 en Environmental sciences. Sin citas hasta agosto de 2018. 


\title{
2.1 SULFATE SOILS STABILIZATION WITH MAGNESIUM-BASED BINDERS
}

\author{
Estabilización de suelos con sulfatos con ligantes a base de magnesio
}

A. Seco, L. Miqueleiz, E. Prieto, S. Marcelino, B. García, P. Urmeneta

Applied Clay Science 135 (2017) 457-464 https://doi.org/10.1016/j.clay.2016.10.033

https://www.sciencedirect.com/science/article/pii/S0169131716304549

Histórico del artículo: Recibido el 1 de agosto de 2016. Recibido revisado el 18 de octubre de 2016. Aceptado el 20 de octubre de 2016. Disponible online el 27 de octubre de 2016.

Titulares

- Existe potencial en el uso de óxido de magnesio como estabilizador de suelos con sulfatos.

- El óxido de magnesio demostró mejor capacidad como activador puzolánico de las GGBS que la cal.

- El ensayo de hinchamiento a largo plazo fue un buen estimador del desarrollo de minerales expansivos.

- Los resultados de XRD concuerdan con la estimación indirecta de la presencia de minerales expansivos.

- Todos los suelos tratados con cal y ninguno de los suelos tratados con PC-8 mostraron un comportamiento expansivo.

\section{Resumen del artículo}

La estabilización de suelos con sulfatos es un tema con implicaciones técnicas, económicas y ambientales muy interesantes. La dificultad de la estabilización de estos suelos se debe al hecho de que los aditivos estabilizadores usuales se basan en calcio. En estos suelos, el sulfato se combina con el calcio del aditivo y el aluminio de la arcilla, lo que resulta en un mineral expansivo altamente hidratado llamado etringita. Esto provoca el hinchamiento del material tratado e incluso su destrucción. Este estudio analiza el resultado de la sustitución del calcio por un aditivo alternativo basado en magnesio que es un subproducto industrial llamado PC-8, en la estabilización de cinco suelos con sulfatos diferentes. Desde un punto de vista mecánico, los suelos tratados con PC-8 alcanzaron valores de resistencia, similares a los tratados con cal, de aproximadamente 2-3 MPa para una dosis del $4 \%$ y 2-5 MPa para una dosis del $8 \%$, siendo generalmente mejores los resultados con el PC-8 que con cal. Cuando el PC-8 se combinó con GGBS, los valores de resistencia aumentaron hasta 11-13 MPa y la cal-GGBS alcanzó los 6-7 MPa. El hinchamiento natural de los suelos tratados con PC-8 disminuyó sustancialmente y se mantuvo constante incluso en inmersión en agua a largo plazo. En el caso de los suelos tratados con cal, el hinchamiento a largo plazo aumentó hasta valores muy altos, incluso en el caso de suelos sin hinchamiento natural. El análisis XRD de estas muestras demostró, de acuerdo con el comportamiento observado de hinchamiento de los suelos cuando se trataron con ambos aditivos, la existencia de etringita en 4 de los 5 suelos cuando se trataron con cal y no hubo minerales expansivos en los suelos tratados con PC-8. Etringita

Palabras clave: Suelo con sulfatos, Estabilización de suelos, Valorización, Material de construcción, 


\title{
2.2 ESTIMATED AND REAL DURABILITY OF UNFIRED CLAY BRICKS: DETERMINING FACTORS AND REPRESENTATIVENESS OF THE LABORATORY TESTS
}

\author{
Durabilidad estimada y real de los ladrillos de arcilla sin cocer: factores \\ determinantes y representatividad de las pruebas de laboratorio
}

A.Seco, P.Urmeneta, E.Prieto, S.Marcelino, B.García, L.Miqueleiz

Construction and Building Materials 131 (Enero 2017) 600-605

http://dx.doi.org/10.1016/j.conbuildmat.2016.11.107

https://ac.els-cdn.com/S0950061816318761/1-s2.0-S0950061816318761-main.pdf?_tid=237efcad-6749-4718-8eee339121b9f85c\&acdnat=1532417252_4ed9f2714c5ba5e79749e33492075c4c

Histórico del artículo: Recibido el 16 de agosto de 2016. Revisado el 15 de noviembre de 2016 . Aceptado el 22 de noviembre de 2016. Disponible online el 29 de noviembre de 2016.

Titulares

- La resistencia mecánica depende del tipo de aditivo, pero no del contenido de arena.

- El ensayo de absorción capilar no es apropiada para estimar la durabilidad real de los materiales de construcción basados en tierra.

- El ensayo de absorción total de agua es un estimador adecuado de durabilidad de materiales de construcción basados en tierra.

- El ensayo de heladicidad, tal como se define en las normas españolas, no es un buen estimador de durabilidad.

- El aditivo PC-8+GGBS obtuvo los mejores resultados de laboratorio y durabilidad real.

\section{Resumen del artículo}

Este artículo presenta un análisis de la representatividad de los principales ensayos de laboratorio y la durabilidad real de los materiales de construcción basados en tierra. Para este estudio, se trató con cemento Porland, cal hidráulica, una mezcla de cal y escoria granulada molida de alto horno y otro ligante compuesto de un residuo con alto contenido de óxido de magnesio mezclado con escoria granulada molida de alto horno, un suelo de marga natural, mezclado con diferentes porcentajes de arena de sílice. Todas las combinaciones se caracterizaron en base a los ensayos de laboratorio habituales relacionados con la durabilidad: densidad máxima, resistencia a la compresión simple, humectación y secado, resistencia a la erosión acelerada de Swinburne, absorción de agua por capilaridad, absorción total de agua y heladicidad. Los resultados de estas pruebas se relacionaron con la durabilidad real de las muestras expuestas durante dieciocho meses al aire libre. Se reveló el efecto positivo de la adición de arena en la durabilidad de los materiales y el gran resultado del ligante a base de óxido de magnesio con escoria granulada molida de alto horno. También se demostró la representatividad de la prueba de absorción de agua como un indicador de durabilidad de la durabilidad de los materiales de construcción basados en tierra.

Palabras clave: Materiales de construcción basados en tierra, Durabilidad, Propiedades mecánicas, Ensayos de laboratorio 


\subsection{SUSTAINABLE UNFIRED BRICKS MANUFACTURING FROM CONSTRUCTION AND DEMOLITION WASTES}

\section{Producción sostenible de ladrillos sin cocer a partir de residuos de construcción y demolición}

A. Seco, J. Omer, S. Marcelino, S. Espuelas, E. Prieto

Construction and Building Materials 167 (2018) 154-165

https://doi.org/10.1016/j.conbuildmat.2018.02.026

Histórico del artículo: Recibido el 21 de agosto de 2017. Recibido revisado el 2 de febrero de 2018. Aceptado el 5 de febrero de 2018. Disponible online el 10 de febrero de 2018.

Titulares

- Los CDW pueden reemplazar los suelos naturales para la fabricación de ladrillos sin cocer.

- La trabajabilidad de las muestras limitaba cada relación de sustitución máxima de CDW.

- Los CDW se pueden combinarse con diferentes ligantes y optimizar las propiedades del ladrillo.

- $\quad$ El LCA permitió cuantificar el impacto ambiental de cada combinación estudiada.

\section{Resumen del artículo}

La gestión de los CDW es un gran desafío para la mayoría de los gobiernos. El mayor componente de éstos son los fragmentos o restos de hormigón y mampostería. Entre los enfoques más comunes para valorizar de estos residuos está convertirlos en áridos reciclados, sin embargo, esto puede verse obstaculizado por la baja calidad de algunos de estos áridos reciclados en comparación con los áridos naturales. Este artículo presenta los resultados de una investigación experimental donde se usaron restos de ladrillos cerámicos y de hormigón para sustituir parcialmente el suelo arcilloso para la producción de ladrillos sin cocer. Los ladrillos obtenidos se sometieron a ensayos de resistencia a compresión, de heladicidad y de absorción de agua. Además, se evaluó el impacto ambiental de los ladrillos producidos en base al LCA. Se estableció que los residuos de hormigón podrían usarse para sustituir hasta el $50 \%$ de la arcilla, mientras que los residuos cerámicos sólo podrían sustituir un máximo del $30 \%$. Se observó que los ladrillos hechos de mezclas de residuos de arcilla y hormigón tenían una resistencia mecánica menor que los hechos de arcilla y restos de ladrillo. En cuanto a la absorción de agua, no hubo apenas diferencia entre las dos mezclas de ladrillos; sin embargo, la reducción en la resistencia tras la inmersión en agua fue ligeramente mayor en los ladrillos que contenían residuos de hormigón que los que contenían residuos cerámicos. Además, los ensayos mostraron que el comportamiento en el ensayo de heladicidad fue mejor en ladrillos con hormigón que en aquellos que incorporaban restos de ladrillos. El LCA de vida demostró que es fundamentalmente el contenido de ligante lo que determina el impacto ambiental de los ladrillos estudiados. Por último, se demostró que, de las combinaciones ensayadas, la los ligantes CL-90-S+GGBS 2/8 fue la más adecuada desde los puntos de vista técnico y ambiental.

Palabras clave: Ladrillos no cocidos, Residuos de construcción y demolición, Reacciones puzolánicas, Propiedades mecánicas, Durabilidad, Análisis del ciclo de vida 


\subsection{TECHNICAL AND ENVIRONMENTAL CHARACTERIZATION OF HYDRAULIC AND ALKALINE BINDERS}

\section{Caracterización técnica y ambiental de cementantes hidráulicos y alcalinos}

S. Espuelas, A.M. Echeverria, S. Marcelino, E. Prieto, A. Seco

Journal of Cleaner Production 196 (2018) 1306-1313https://doi.org/10.1016/j.jclepro.2018.06.090

https://ac.els-cdn.com/S0959652618317402/1-s2.0-S0959652618317402-main.pdf?_tid=faec8686-31f6-4f98-bd7439e13bc65b61\&acdnat=1532418032_5c398568264e412216464abd5a5bf0b3

Histórico del artículo: Recibido el 26 de marzo de 2018. Recibido revisado el 28 de mayo de 2018. Aceptado el 10 de junio de 2018. Disponible online el 12 de junio de 2018.

Titulares

- Los morteros hidráulicos tuvieron tiempos de inicio de fraguado más largos que los alcalinos.

- Los tiempos de fraguado fueron similares para los morteros hidráulicos y los alcalinos.

- Los ligantes hidráulicos requieren más agua añadida que los alcalinos.

- Las GGBS permiten la fabricación de ligantes activados alcalinos de alta resistencia.

- Las GGBS y las FA disminuyen el impacto relacionado con la fabricación de ligantes.

\section{Resumen del artículo}

El cemento Portland es un ligante ampliamente utilizado en aplicaciones de construcción y edificación debido a sus buenas propiedades. A pesar de su conveniencia como material de construcción, las demandas sociales y las tendencias de las políticas están solicitando un impacto menor y una industria de fabricación de cemento más sostenible. Las formas más efectivas para alcanzar este objetivo son la sustitución del clinker por diferentes desechos o subproductos en la composición del cemento o el desarrollo de cementantes más sostenibles como los ligantes activados alcalinamente. Este trabajo analiza desde un punto de vista técnico y ambiental la sustitución de un cemento común CEM I constituido por clinker para la fabricación de morteros de construcción. Se consideraron cuatro cementos comunes con diferentes contenidos de escoria granulada molida de alto horno (GGBS) o cenizas volantes (FA), así como quince combinaciones de ligantes activados alcalinamente (AAB). Se llevaron a cabo pruebas de consistencia, densidad, resistencia a la compresión (CS) y análisis del ciclo de vida para establecer la capacidad de estos diferentes ligantes hidráulicos y alcalinos para la sustitución del cemento Portland CEM I. Los resultados obtenidos demostraron la conveniencia técnica y ambiental de estos ligantes para la fabricación de morteros de construcción.

Palabras clave: Mortero, Ligante activado alcalinamente, Cemento hidráulico, Valorización de residuos, Escoria granulada molida de alto horno, Cenizas volantes, Análisis del ciclo de vida 



\section{CONCLUSIONES}

En este capítulo de Conclusiones se presentaran, en primer lugar de manera individualizada, las asociadas a los objetivos principales de la Tesis, y -para acabar- las conclusiones finales.

\subsection{ESTABILIZACIÓN DE SUELOS CON SULFATOS}

La estabilización de los suelos con sulfatos es un tema muy interesante debido a sus implicaciones técnicas, económicas y ambientales. Desde un punto de vista técnico, su estabilización continúa siendo un desafío debido a la concurrencia muchas veces de circunstancias que los hacen malos materiales de construcción y la imposibilidad práctica de su estabilización con aditivos convencionales. En este sentido, los resultados obtenidos en este estudio han permitido responder algunas de las preguntas clave sobre el efecto del magnesio en diferentes tipos de suelos con sulfatos, entre ellos:

1. El tratamiento de los suelos naturales con 4 y $8 \%$ de cal o PC- 8 mejoró sus propiedades mecánicas hasta los valores habituales obtenidos en otros suelos arcillosos sin sulfatos. En todos los casos las resistencias mecánicas obtenidas fueron mayores para las dosificaciones del $8 \%$ que para las del $4 \%$, y para el PC-8 que para la cal, demostrando que la capacidad del magnesio como aditivo estabilizador de arcilla desde un punto de vista mecánico es mayor que la cal.

2. El uso del ligante combinado de cal+GGBS o del PC-8+GGBS mejoró en todos los casos las propiedades mecánicas de los suelos tratados, incluso antes de los 28 días de curado. Las combinaciones de PC-8+GGBS alcanzaron, en todos los suelos tratados, los mejores resultados mecánicos en todos los tiempos de curado, demostrando una mejor capacidad del magnesio como aditivo activador de las reacciones puzolánicas que el calcio.

3. Ninguna de las muestras preparadas durante los 90 días de curado en cámara húmeda mostró daño significativo o falta de resistencia en el ensayo a compresión simple. Sólo después de esa edad, todas las muestras restantes tratadas con cal del suelo $V$ fueron hinchándose hasta los 160 días de curado, momento en el que se desintegraron por completo. Esto a pesar de que el análisis por XRD de estas muestras no mostró la presencia de minerales expansivos en ellas.

4. La prueba de hinchamiento a largo plazo demostró su capacidad como estimador indirecto del desarrollo potencial de minerales expansivos en los suelos con sulfatos tratados. En las muestras tratadas con un $8 \%$ de cal, sólo en el caso del suelo III, el hinchamiento observado del $7 \%$ no concuerda con la no detección de 
etringita por XRD. En las muestras tratadas con $8 \%$ de PC-8 se observó una reducción significativa del hinchamiento natural, así como de la estabilidad dimensional a largo plazo de todas las muestras tratadas, excepto en el caso del suelo IV para el que se observó un pequeño hinchamiento. En ninguna de las muestras tratadas con PC-8 se identificaron minerales expansivos mediante análisis por XRD. 


\subsection{DURABILIDAD DE MATERIALES DE CONSTRUCCIÓN BASADOS EN TIERRA}

Este estudio experimental permitió obtener las siguientes conclusiones:

1. El contenido de arena de las muestras no tiene relación con su resistencia mecánica, que claramente depende del tipo de aditivo usado.

2. Aunque todas las combinaciones excedieron ampliamente el valor mínimo de resistencia a compresión simple establecido en la norma española, en este ensayo, los mejores resultados se obtuvieron con las combinaciones que incluyen PC-8+GGBS y PC, seguidas de cerca por la CL-90-S+GGBS y en menor medida por el NHL-5. Si se compara la resistencia de cada aditivo con la durabilidad observada en el exterior, se puede afirmar que la relación resistencia-durabilidad se cumplió para todos los aditivos, excepto en PC, en el que la resistencia no fue un buen indicador de su durabilidad.

3. Los ciclos de humectación y secado y los ensayos de erosión acelerada de Swinburne demostraron ser pruebas poco exigentes y no ser representativas de la durabilidad observada, por lo que no pueden considerarse adecuados para la estimación de la durabilidad de los EBCM.

4. En el ensayo de absorción por capilaridad, el resultado del comportamiento de los aditivos se ajusta al patrón de la durabilidad observada en el exterior: se obtuvieron las menores absorciones de agua con PC-8+GGBS, seguido del PC y CL$90-S+G G B S$ y finalmente del NHL-5. Sin embargo, el aumento en el contenido de arena de las muestras aumentó significativamente la absorción de agua por capilaridad, lo que proporciona un resultado opuesto a la durabilidad observada, que aumentó con el porcentaje de arena. Esto indica que este ensayo no es apropiado para estimar la durabilidad real de los EBCM.

5. En el caso del ensayo de absorción total de agua, tanto el comportamiento de los aditivos como los porcentajes de arena, coinciden con el patrón observado en el ensayo al aire libre. Esto permite establecer este ensayo como un estimador adecuado de la durabilidad de los EBCM.

6. Durante el ensayo de ciclos de congelación/descongelación, los daños sólo ocurrieron en muestras tratadas con NHL-5, en primer lugar para las no impermeabilizadas y luego para las impermeabilizadas, con una clara influencia del contenido de arena en la resistencia al ciclado. El hecho de que cualquier muestra con otros ligantes no resulte dañada pone de relieve la poca discriminación de esta prueba para determinar los aditivos más adecuados, o al menos con el número de ciclos considerados representativos por la norma española.

7. Durante el ensayo de exposición a la intemperie, desde la semana 70 , no se dañaron más muestras. Esto muestra que las combinaciones que alcanzaron esta edad sin daños superficiales tienen algunas propiedades que permiten suponer que son duraderas en condiciones exteriores. 


\subsection{LADRILLOS NO COCIDOS A PARTIR DE RESIDUOS DE CONSTRUCCIÓN Y DEMOLICIÓN}

De esta investigación experimental, sobre la fabricación de ladrillos no cocidos a partir de CDW, se podría concluir:

1. Las fracciones finas de CDW de hormigón y cerámica, como sustitutos del suelo de marga natural, modificaron las propiedades físicas del relleno y las reacciones químicas que ocurren en los ladrillos no cocidos.

2. La tasa máxima de sustitución para cada tipo de residuo fue diferente debido a los requisitos de trabajabilidad para la fabricación de mezclas. Por lo tanto, para los CDW de hormigón, la tasa máxima de sustitución fue del 50\%, mientras que para los CDW cerámicos, sólo fue posible una tasa de sustitución del $30 \%$.

3. En el caso de las combinaciones de relleno basadas en el hormigón, la UCS a la edad de 28 días disminuyó el $13.4 \%$ en relación con el suelo puro, cuando ambas combinaciones fueron tratadas con el $10 \%$ de PC. En el caso de relleno basado en cerámica, el valor UCS final cuando se utilizaron el mismo ligante y dosificación, superó el valor de referencia en un $4,1 \%$, lo que demuestra una mayor reactividad química del residuo cerámico en comparación con el basado en hormigón.

4. La prueba de UCS después de $24 \mathrm{~h}$ de inmersión en agua mostró una sensibilidad más baja de los residuos con rellenos basados en material cerámico que los del hormigón.

5. Ninguno de los dos tipos de relleno mostró una tendencia clara en sus valores de UCS con el tiempo de curado, así como valores anómalos a edades de curado intermedias. Esto se debe a procesos complejos de floculación-hidratacióncementación en las diferentes combinaciones, así como a la modificación de las propiedades físicas del relleno.

6. Ambos residuos de ensayo arrojaron valores finales similares de absorción de agua a pesar de las diferentes tasas de sustitución. En las edades de curado intermedias, las combinaciones con relleno con residuos cerámicos mostraron cambios en la absorción de agua debido al proceso de hidratación de los ligantes.

7. Aunque en las combinaciones basadas en hormigón, las pérdidas de UCS después de $24 \mathrm{~h}$ de inmersión en agua fueron mucho más altas que en las basadas en ladrillos triturados, el rendimiento en el ensayo de heladicidad fue mejor.

8. Estos resultados muestran la complejidad de las relaciones entre propiedades mecánicas, absorción de agua y la durabilidad como parámetros clave para la caracterización de este tipo de materiales. Esto destaca que los resultados de las pruebas deben interpretarse cuidadosamente para una caracterización correcta de este tipo de materiales de construcción desde un punto de vista técnico.

9. El LCA mostró el impacto ambiental de cada combinación en función del $\mathrm{CO}_{2}$ liberado y la energía consumida durante todo el proceso de producción. Los impactos ambientales absolutos de las combinaciones dependen principalmente de los impactos de producción de los ligantes y su dosificación. El efecto del tipo de relleno se basa sólo en la sustitución del suelo natural por los CDW. Así, las combinaciones basadas en cemento Portland resultaron tener los mayores 
impactos absolutos, ya sea en emisiones de $\mathrm{CO}_{2}$ o en energía consumida, mientras que los resultados más bajos correspondieron a las combinaciones más ricas de GGBS.

10. Si se tienen en cuenta las propiedades mecánicas de cada combinación, el CL-90$\mathrm{S}$ aparece como como la peor combinación desde un punto de vista ambiental, mientras que las GGBS tienen los menores impactos por unidad de resistencia (MPa).

11. El análisis de LCA permitió cuantificar el impacto relacionado con la fabricación de cada combinación. 


\subsection{MORTEROS CON LIGANTES ACTIVADOS ALCALINAMENTE}

Esta investigación experimental permitió establecer las diferencias técnicas y ambientales entre los ligantes hidráulicos y alcalinos para la fabricación de morteros. Con base en las propiedades en fresco, la resistencia mecánica tras el tiempo de curado y el análisis ambiental realizado, se obtuvieron las siguientes conclusiones específicas:

1. Los morteros hidráulicos tienen un tiempo de inicio de fraguado más largo que los alcalinos. En el caso de los morteros hidráulicos, el inicio del tiempo de fraguado no estaba relacionado con los valores de resistencia a compresión. A pesar de estar relacionado con la composición del cemento, las diferencias en la composición de los cinco cementos del estudio no son lo suficientemente grandes como para apreciarse. Por otra parte, los morteros activados alcalinamente mostraron tiempos de inicio de fraguado más cortos con relaciones inversas con el contenido de GGBS y molaridades de los activadores.

2. A pesar de las diferencias de tiempo de fraguado inicial observadas, los períodos de fraguado fueron similares y no mostraron ningún patrón ni para los morteros hidráulicos ni para los alcalinos.

3. Las combinaciones hidráulicas requerían mayor cantidad de agua añadida para alcanzar la consistencia para una trabajabilidad adecuada debido a la falta de otras fuentes de agua en las mezclas. Los morteros alcalinos mostraron una relación inversa entre las necesidades de agua añadida y el contenido de FA y la molaridad del activador.

4. Las densidades alcanzadas fueron muy parecidas entre los morteros hidráulicos. En general, las combinaciones con ligantes activados alcalinamente mostraron valores ligeramente más altos, cuando el contenido de GGBS también lo era.

5. Los morteros hidráulicos mostraron patrones de aumento de la CS regulares a lo largo del tiempo de curado, excepto para la combinación CEM I 52.5, para la que el aumento principal de resistencia ocurrió antes de los 14 días de edad. Los valores finales de la CS dependieron de las propiedades de resistencia del cemento, con cierta variabilidad entre los tres cementos de 32,5 MPa considerados. Por otro lado, los morteros alcalinos mostraron valores de la CS directamente relacionados con el contenido de GGBS de los precursores e inversamente relacionados con el contenido de FA. Las propiedades mecánicas mostraron fuertes aumentos en todas las edades de ensayo, para todas las molaridades incluso para el contenido más bajo de GGBS. Esto demostró la conveniencia de este precursor para la fabricación de ligantes activados alcalinamente de alta resistencia. El activador que contiene $\mathrm{NaOH} 6 \mathrm{M}$ alcanzó los mejores resultados mecánicos, demostrando que esta molaridad crea las condiciones óptimas para las polimerizaciones de los precursores considerados.

6. Desde un punto de vista ambiental, los resultados obtenidos para los diferentes morteros fueron diferentes cuando se consideraron datos no normalizados 0 normalizados. Los resultados no normalizados muestran los impactos de la combinación para cada categoría. Así, la combinación CEM I 52.5 alcanza los peores impactos en tres de las cuatro categorías ambientales, a excepción de la categoría de emisiones de polvo debido a los mayores impactos en esta categoría de los compuestos activadores alcalinos. En base a este punto de vista, no existe una combinación claramente más ambiental porque la mejor combinación cambia, dependiendo de las categorías de impacto. Cuando se consideran los resultados normalizados, el FA 10M 
se convierte en la peor combinación para todas las categorías de impacto, debido a las pobres propiedades mecánicas demostradas cuando el FA era el único compuesto del precursor. El GGBS 6M alcanzó los mejores valores para la acidificación y la eutrofización, y se acercó a los mejores valores para las categorías de cambio climático y de impacto del polvo, demostrando ser la mejor combinación global desde el punto de vista ambiental. 


\subsection{CONCLUSIONES FINALES}

Se puede afirmar que el uso de aditivos basados en magnesio potencialmente puede ser un buen método para la valorización de materiales que contienen sulfato en aplicaciones de construcción. Aunque se deben llevar a cabo más estudios en este sentido, los resultados obtenidos en este estudio sugieren la posibilidad de sustituir los aditivos basados en calcio por los basados en magnesio.

Se puede destacar el efecto positivo sobre la durabilidad de los materiales de la adición de arena, el buen resultado del aglutinante compuesto por PC-8+GGBS, así como la representatividad de la prueba de absorción de agua como estimador de la durabilidad de los EBCM.

La sustitución de parte de un suelo natural por rellenos reciclados modifica las reacciones químicas entre el relleno y el ligante. Esto podría tenerse en cuenta para adecuar la formulación del relleno, el tipo de ligante y la selección de su dosis para optimizar la fabricación de ladrillos sin cocer desde los puntos de vista técnico y ambiental.

Se puede afirmar que los cementos comunes que contienen GGBS y FA como sustitutivos del clínker, así como los ligantes activados alcalinamente, pueden ser formas efectivas para, manteniendo las propiedades técnicas de este material, disminuir el impacto medioambiental relacionado con la fabricación de morteros de construcción convencionales. 


\section{BIBLIOGRAFÍA}

AENOR. (1993a). UNE 103400:1993 Ensayo de rotura a compresión simple en probetas de suelo.

AENOR. (1993b). UNE 103104:1993 Determinación del límite plástico de un suelo.

AENOR. (1994a). UNE 103103:1994 Determinación del límite liquido de un suelo por el método del aparato de Casagrande.

AENOR. (1994b). UNE 103500:1994 Geotecnia. Ensayo de compactación Proctor normal.

AENOR. (1996). UNE 103601:1996 Ensayo del hinchamiento libre de un suelo en edómetro.

AENOR. (1997). UNE 67028:1997 EX Ladrillos cerámicos de arcilla cocida. Ensayo de heladicidad.

AENOR. (2008). UNE 41410:2008 Bloques de tierra comprimida para muros y tabiques. Definiciones especificaciones y métodos de ensayo.

Aïtcin, P.C. (2014). Binders for durable and sustainable concrete. Nueva York: CRC Press. ISBN: 9781482265767

Al-Rawas, A. A. (1999). The factors controlling the expansive nature of the soils and rocks of northern Oman. Engineering Geology, 53(3-4), 327-350.

http://doi.org/10.1016/S0013-7952(98)00085-4

Alam, I., Naseer, A., y Shah, A. A. (2015). Economical stabilization of clay for earth buildings construction in rainy and flood prone areas. Construction and Building Materials, 77, 154-159. http://doi.org/10.1016/J.CONBUILDMAT.2014.12.046

Althaus, H., Chudacoff, M., Hischier, R., Jungbluth, N., Osses, M., Primas, A., y Hellweg, S. (2007). Life cycle inventories of chemicals. Final report ecoinvent data v2.0. Swiss Centre for Life Cycle Inventories, (8), 1-957. Recuperado a partir de https://db.ecoinvent.org/reports/08_Chemicals.pdf

Andrade, C., y Buják, R. (2013). Effects of some mineral additions to Portland cement on reinforcement corrosion. Cement and Concrete Research, 53, 59-67.

http://doi.org/10.1016/J.CEMCONRES.2013.06.004

ASTM. (2017). ASTM C618-17a Standard Specification for Coal Fly Ash and Raw or Calcined Natural Pozzolan for Use in Concrete. ASTM.

Aubert, J. E., Fabbri, A., Morel, J. C., y Maillard, P. (2013). An earth block with a compressive strength higher than $45 \mathrm{MPa}$ ! Construction and Building Materials, 47, 


\section{6-369. http://doi.org/10.1016/J.CONBUILDMAT.2013.05.068}

Babaee, M., y Castel, A. (2016). Chloride-induced corrosion of reinforcement in lowcalcium fly ash-based geopolymer concrete. Cement and Concrete Research, 88, 96107. http://doi.org/10.1016/J.CEMCONRES.2016.05.012Bellmann, F., y Stark, J. (2009). Activation of blast furnace slag by a new method. Cement and Concrete Research, 39(8), 644-650. http://doi.org/10.1016/J.CEMCONRES.2009.05.012

Bravo, M., de Brito, J., Pontes, J., y Evangelista, L. (2015). Durability performance of concrete with recycled aggregates from construction and demolition waste plants. Construction and Building Materials, 77, 357-369. http://doi.org/10.1016/J.CONBUILDMAT.2014.12.103

Butera, S., Hyks, J., Christensen, T. H., y Astrup, T. F. (2015). Construction and demolition waste: Comparison of standard up-flow column and down-flow lysimeter leaching tests. Waste Management, 43, 386-397. http://doi.org/10.1016/J.WASMAN.2015.04.032

Cambridge Econometrics. (2014). Study on modelling of the economic and environmental impacts of raw material consumption. Technical Report 2014-2478. European Commission. http://doi.org/10.2779/74169

Cardoso, R., Silva, R. V., Brito, J. de, y Dhir, R. (2016). Use of recycled aggregates from construction and demolition waste in geotechnical applications: A literature review. Waste Management, 49, 131-145. http://doi.org/10.1016/J.WASMAN.2015.12.021

Celik, E., y Nalbantoglu, Z. (2013). Effects of ground granulated blastfurnace slag (GGBS) on the swelling properties of lime-stabilized sulfate-bearing soils. Engineering Geology, 163, 20-25. http://doi.org/10.1016/J.ENGGEO.2013.05.016

CEMBUREAU. (2016). Activity Report 2016, 36. Recuperado a partir de https://cembureau.eu/media/1635/activity-report-2016.pdf

CEN. (2000a). UNE-EN 1015-11:2000 Métodos de ensayo de los morteros para albañilería. Parte 11: Determinación de la resistencia a flexión y a compresión del mortero endurecido.

CEN. (2000b). UNE-EN 1015-3:2000 Métodos de ensayo para morteros de albañilería. Parte 3: Determinación de la consistencia del mortero fresco (por la mesa de sacudidas).

CEN. (2002). UNE-EN 13139:2003 Áridos para morteros.

CEN. (2004). UNE-EN 13139/AC:2004 Áridos para morteros.

CEN. (2007a). UNE-EN 1015-11:2000/A1:2007 Métodos de ensayo de los morteros para albañilería. Parte 11: Determinación de la resistencia a flexión y a compresión del mortero endurecido. 
CEN. (2007b). UNE-EN 480-2:2007 Aditivos para hormigones morteros y pastas Métodos de ensayo. Parte 2: Determinación del tiempo de fraguado.

CEN. (2009). UNE-EN 12620:2003+A1:2009 Áridos para hormigón.

CEN. (2011a). UNE-EN 197-1:2011 Cemento. Parte 1: Composición especificaciones y criterios de conformidad de los cementos comunes.

CEN. (2011b). UNE-EN 772-11:2011 Métodos de ensayo de piezas para fábrica de albañilería. Parte 11: Determinación de la absorción de agua por capilaridad de piezas para fábrica de albañilería de hormigón, hormigón celular curado en autoclave, piedra artificial y piedra natural, y de la tasa de absorción de agua inicial de las piezas de arcilla cocida para fábrica de albañilería.

CEN. (2011c). UNE-EN 772-21:2011 Métodos de ensayo de piezas para fábricas de albañilería. Parte 21: Determinación de la absorción de agua de piezas para fábrica de albañilería de arcilla cocida y silicocalcáreas por absorción de agua fría.

CEN. (2016). UNE-EN 459-1:2016 Cales para la construcción. Parte 1: Definiciones especificaciones y criterios de conformidad.

Chen, C., Habert, G., Bouzidi, Y., y Jullien, A. (2010). Environmental impact of cement production: detail of the different processes and cement plant variability evaluation. Journal of Cleaner Production, 18(5), 478-485. http://doi.org/10.1016/J.JCLEPRO.2009.12.014

Chen, J., y Jiang, M. (2009). Long-term evolution of delayed ettringite and gypsum in Portland cement mortars under sulfate erosion. Construction and Building Materials, 23(2), 812-816. http://doi.org/10.1016/J.CONBUILDMAT.2008.03.002

Chen, L., y Lin, D.-F. (2009). Stabilization treatment of soft subgrade soil by sewage sludge ash and cement. Journal of Hazardous Materials, 162(1), 321-327. http://doi.org/10.1016/J.JHAZMAT.2008.05.060

Ciancio, D., Jaquin, P., y Walker, P. (2013). Advances on the assessment of soil suitability for rammed earth. Construction and Building Materials, 42, 40-47. http://doi.org/10.1016/J.CONBUILDMAT.2012.12.049

Cid-Falceto, J., Mazarrón, F. R., y Cañas, I. (2012). Assessment of compressed earth blocks made in Spain: International durability tests. Construction and Building Materials, 37, 738-745. http://doi.org/10.1016/J.CONBUILDMAT.2012.08.019

Ciliberto, E., Ioppolo, S., y Manuella, F. (2008). Ettringite and thaumasite: A chemical route for their removal from cementious artefacts. Journal of Cultural Heritage, 9(1), 30-37. http://doi.org/10.1016/J.CULHER.2007.05.004

Crammond, N. (2002). The occurrence of thaumasite in modern construction - a review. Cement and Concrete Composites, 24(3-4), 393-402. http://doi.org/10.1016/S09589465(01)00092-0 
Damtoft, J. S., Lukasik, J., Herfort, D., Sorrentino, D., y Gartner, E. M. (2008). Sustainable development and climate change initiatives. Cement and Concrete Research, 38(2), 115-127. http://doi.org/10.1016/J.CEMCONRES.2007.09.008

Degirmenci, N., Okucu, A., y Turabi, A. (2007). Application of phosphogypsum in soil stabilization. Building and Environment, 42(9), 3393-3398.

http://doi.org/10.1016/J.BUILDENV.2006.08.010

Dunlap, R. (2003). Life cycle inventory of slag cement manufacturing process: project CTL. Construction Technology Laboratories, Illinois, 13.

Escadeillas, G., Aubert, J.-E., Segerer, M., y Prince, W. (2007). Some factors affecting delayed ettringite formation in heat-cured mortars. Cement and Concrete Research, 37(10), 1445-1452. http://doi.org/10.1016/J.CEMCONRES.2007.07.004

España. MINISTERIO DE LA PRESIDENCIA. (2008). REAL DECRETO 1247/2008, de 18 de julio, por el que se aprueba la instrucción de hormigón estructural (EHE-08), 3517635178. http://doi.org/10.1017/CBO9781107415324.004

European Commission. (2018a). Market, Industry, Entrepreneurship and SMEs: Cement and Lime - European Commission. Recuperado a partir de https://ec.europa.eu/growth/sectors/raw-materials/industries/nonmetals/cement-lime_en

European Commission. (2018b). Climate Action - European Commission. Recuperado a partir de https://ec.europa.eu/clima/index_en

Fernández-Jiménez, A., Palomo, A., Sobrados, I., y Sanz, J. (2006). The role played by the reactive alumina content in the alkaline activation of fly ashes. Microporous and Mesoporous Materials, 91(1-3), 111-119. http://doi.org/10.1016/J.MICROMESO.2005.11.015

Ferreira, W. L., Reis, É. L., y Lima, R. M. F. (2015). Incorporation of residues from the minero-metallurgical industry in the production of clay-lime brick. Journal of Cleaner Production, 87, 505-510. http://doi.org/10.1016/J.JCLEPRO.2014.09.013

Gala, A. B., Raugei, M., Ripa, M., y Ulgiati, S. (2015). Dealing with waste products and flows in life cycle assessment and emergy accounting: Methodological overview and synergies. Ecological Modelling, 315, 69-76.

http://doi.org/10.1016/J.ECOLMODEL.2015.03.004

Göktepe, A. B., Sezer, A., Sezer, G. I.., y Ramyar, K. (2008). Classification of timedependent unconfined strength of fly ash treated clay. Construction and Building Materials, 22(4), 675-683. http://doi.org/10.1016/J.CONBUILDMAT.2006.10.008

Grist, E. R., Paine, K. A., Heath, A., Norman, J., y Pinder, H. (2015). The environmental credentials of hydraulic lime-pozzolan concretes. Journal of Cleaner Production, 93, 26-37. http://doi.org/10.1016/J.JCLEPRO.2015.01.047 
Guillaud, H., y Houben, H. (2006). Traité de construction en terre. (3a ed.) CRATerre. Marsella: Parentèses ISBN: 2863641611

Guney, Y., Sari, D., Cetin, M., y Tuncan, M. (2007). Impact of cyclic wetting-drying on swelling behavior of lime-stabilized soil. Building and Environment, 42(2), 681-688. http://doi.org/10.1016/J.BUILDENV.2005.10.035

Habert, G., y Roussel, N. (2009). Study of two concrete mix-design strategies to reach carbon mitigation objectives. Cement and Concrete Composites, 31(6), 397-402. http://doi.org/10.1016/J.CEMCONCOMP.2009.04.001

Habert, G., d'Espinose de Lacaillerie, J. B., y Roussel, N. (2011). An environmental evaluation of geopolymer based concrete production: reviewing current research trends. Journal of Cleaner Production, 19(11), 1229-1238.

http://doi.org/10.1016/J.JCLEPRO.2011.03.012

Hanjitsuwan, S., Phoo-ngernkham, T., Li, L., Damrongwiriyanupap, N., y Chindaprasirt, P. (2018). Strength development and durability of alkali-activated fly ash mortar with calcium carbide residue as additive. Construction and Building Materials, 162, 714-723. http://doi.org/10.1016/J.CONBUILDMAT.2017.12.034

Heijungs, R., Guinee, J. B., Huppes, G., Lankreijer, R. M., Udo, D. H., Sleeswijk, A. W., Goede, H. P. (1992a). Environmental Life Cycle Assessment of Products - Vol1: Guide. (L. CML, Ed.). Recuperado a partir de https://openaccess.leidenuniv.nl/handle/1887/8061

Heijungs, R., Guinee, J. B., Huppes, G., Lankreijer, R. M., Udo, D. H., Sleeswijk, A. W., Goede, H. P. (1992b). Environmental Life Cycle Assessment of Products - Vol 2: Backgrounds. (L. CML, Ed.). Recuperado a partir de https://openaccess.leidenuniv.nl/handle/1887/8062

ISO. (2006). UNE-EN ISO 14044:2006 Gestión ambiental. Análisis del ciclo de vida. Requisitos y directrices (ISO 14044:2006).

Juenger, M. C. G., Winnefeld, F., Provis, J. L., y Ideker, J. H. (2011). Advances in alternative cementitious binders. Cement and Concrete Research, 41(12), 1232-1243. http://doi.org/10.1016/J.CEMCONRES.2010.11.012

Kellenberger, D., y Althaus, H.-J. (2009). Relevance of simplifications in LCA of building components. Building and Environment, 44(4), 818-825.

http://doi.org/10.1016/J.BUILDENV.2008.06.002

Khan, M. S. H., Castel, A., Akbarnezhad, A., Foster, S. J., y Smith, M. (2016). Utilisation of steel furnace slag coarse aggregate in a low calcium fly ash geopolymer concrete. Cement and Concrete Research, 89, 220-229. http://doi.org/10.1016/J.CEMCONRES.2016.09.001

Kinuthia, J. ., Wild, S., y Jones, G. . (1999). Effects of monovalent and divalent metal sulphates on consistency and compaction of lime-stabilised kaolinite. Applied Clay 
Science, 14(1-3), 27-45. http://doi.org/10.1016/S0169-1317(98)00046-5

Kinuthia, J. M., y Oti, J. E. (2012). Designed non-fired clay mixes for sustainable and low carbon use. Applied Clay Science, 59-60, 131-139.

http://doi.org/10.1016/J.CLAY.2012.02.021

Labat, M., Magniont, C., Oudhof, N., y Aubert, J.-E. (2016). From the experimental characterization of the hygrothermal properties of straw-clay mixtures to the numerical assessment of their buffering potential. Building and Environment, 97, 6981. http://doi.org/10.1016/J.BUILDENV.2015.12.004

Le Saoût, G., Lothenbach, B., Hori, A., Higuchi, T., y Winnefeld, F. (2013). Hydration of Portland cement with additions of calcium sulfoaluminates. Cement and Concrete Research, 43, 81-94. http://doi.org/10.1016/J.CEMCONRES.2012.10.011

Ledesma, E. F., Jiménez, J. R., Ayuso, J., Fernández, J. M., y de Brito, J. (2015). Maximum feasible use of recycled sand from construction and demolition waste for eco-mortar production - Part-I: ceramic masonry waste. Journal of Cleaner Production, 87, 692706. http://doi.org/10.1016/J.JCLEPRO.2014.10.084

Lee, H., Cody, R. D., Cody, A. M., y Spry, P. G. (2005). The formation and role of ettringite in lowa highway concrete deterioration. Cement and Concrete Research, 35(2), 332343. http://doi.org/10.1016/J.CEMCONRES.2004.05.029

Li, G., Xu, X., Chen, E., Fan, J., y Xiong, G. (2015). Properties of cement-based bricks with oyster-shells ash. Journal of Cleaner Production, 91, 279-287. http://doi.org/10.1016/J.JCLEPRO.2014.12.023

Lin, D.-F., Lin, K.-L., Hung, M.-J., y Luo, H.-L. (2007). Sludge ash/hydrated lime on the geotechnical properties of soft soil. Journal of Hazardous Materials, 145(1-2), 58-64. http://doi.org/10.1016/J.JHAZMAT.2006.10.087

Liu, Z., Chen, Q., Xie, X., Xue, G., Du, F., Ning, Q., y Huang, L. (2011). Utilization of the sludge derived from dyestuff-making wastewater coagulation for unfired bricks. Construction and Building Materials, 25(4), 1699-1706. http://doi.org/10.1016/J.CONBUILDMAT.2010.10.012

Lorca, P., Calabuig, R., Benlloch, J., Soriano, L., y Payá, J. (2014). Microconcrete with partial replacement of Portland cement by fly ash and hydrated lime addition. Materials \& Design, 64, 535-541. http://doi.org/10.1016/J.MATDES.2014.08.022

Maddalena, R., Roberts, J. J., y Hamilton, A. (2018). Can Portland cement be replaced by low-carbon alternative materials? A study on the thermal properties and carbon emissions of innovative cements. Journal of Cleaner Production, 186, 933-942. http://doi.org/10.1016/J.JCLEPRO.2018.02.138

Marcelino-Sadaba, S., Kinuthia, J., Oti, J., y Seco Meneses, A. (2017). Challenges in Life Cycle Assessment (LCA) of stabilised clay-based construction materials. Applied Clay Science, 144, 121-130. http://doi.org/10.1016/J.CLAY.2017.05.012 
McLellan, B. C., Williams, R. P., Lay, J., van Riessen, A., y Corder, G. D. (2011). Costs and carbon emissions for geopolymer pastes in comparison to ordinary portland cement. Journal of Cleaner Production, 19(9-10), 1080-1090.

http://doi.org/10.1016/J.JCLEPRO.2011.02.010

Min, Y., Jueshi, Q., y Ying, P. (2008). Activation of fly ash-lime systems using calcined phosphogypsum. Construction and Building Materials, 22(5), 1004-1008. http://doi.org/10.1016/J.CONBUILDMAT.2006.12.005

Miqueleiz, L., Ramírez, F., Seco, A., Nidzam, R. M., Kinuthia, J. M., Tair, A. A., y Garcia, R. (2012). The use of stabilised Spanish clay soil for sustainable construction materials. Engineering Geology, 133-134, 9-15. http://doi.org/10.1016/J.ENGGEO.2012.02.010

Miqueleiz, L., Ramirez, F., Oti, J. E., Seco, A., Kinuthia, J. M., Oreja, I., y Urmeneta, P. (2013). Alumina filler waste as clay replacement material for unfired brick production. Engineering Geology, 163, 68-74. http://doi.org/10.1016/J.ENGGEO.2013.05.006

Misra, A., Biswas, D., y Upadhyaya, S. (2005). Physico-mechanical behavior of selfcementing class C fly ash-clay mixtures. Fuel, 84(11), 1410-1422. http://doi.org/10.1016/J.FUEL.2004.10.018

Mobili, A., Belli, A., Giosuè, C., Bellezze, T., y Tittarelli, F. (2016). Metakaolin and fly ash alkali-activated mortars compared with cementitious mortars at the same strength class. Cement and Concrete Research, 88, 198-210. http://doi.org/10.1016/J.CEMCONRES.2016.07.004

Mohamed, A. M. O. (2000). The role of clay minerals in marly soils on its stability. Engineering Geology, 57(3-4), 193-203. http://doi.org/10.1016/S00137952(00)00029-6

Muntohar, A. S. (2011). Engineering characteristics of the compressed-stabilized earth brick. Construction and Building Materials, 25(11), 4215-4220. http://doi.org/10.1016/J.CONBUILDMAT.2011.04.061

Naganathan, S., Mohamed, A. Y. O., y Mustapha, K. N. (2015). Performance of bricks made using fly ash and bottom ash. Construction and Building Materials, 96, 576-580. http://doi.org/10.1016/J.CONBUILDMAT.2015.08.068

Nalbantoğlu, Z. (2004). Effectiveness of Class C fly ash as an expansive soil stabilizer. Construction and Building Materials, 18(6), 377-381. http://doi.org/10.1016/J.CONBUILDMAT.2004.03.011

Nguyen, V.-H., Leklou, N., Aubert, J.-E., y Mounanga, P. (2013). The effect of natural pozzolan on delayed ettringite formation of the heat-cured mortars. Construction and Building Materials, 48, 479-484. http://doi.org/10.1016/J.CONBUILDMAT.2013.07.016

Nobst, P., y Stark, J. (2003). Investigations on the influence of cement type on thaumasite formation. Cement and Concrete Composites, 25(8), 899-906. 


\section{http://doi.org/10.1016/S0958-9465(03)00118-5}

Norman, R. L., Dann, S. E., Hogg, S. C., y Kirk, C. A. (2013). Synthesis and structural characterisation of new ettringite and thaumasite type phases: $\mathrm{Ca} 6[\mathrm{Ga}(\mathrm{OH}) 6 \cdot 12 \mathrm{H} 2 \mathrm{O}] 2(\mathrm{SO} 4) 3 \cdot 2 \mathrm{H} 2 \mathrm{O}$ and $\mathrm{Ca} 6[\mathrm{M}(\mathrm{OH}) 6 \cdot 12 \mathrm{H} 2 \mathrm{O}] 2(\mathrm{SO} 4) 2(\mathrm{CO} 3) 2, \mathrm{M}=\mathrm{Mn}$, Sn. Solid State Sciences, 25, 110-117. http://doi.org/10.1016/J.SOLIDSTATESCIENCES.2013.08.006

O'Brien, K. R., Ménaché, J., y O'Moore, L. M. (2009). Impact of fly ash content and fly ash transportation distance on embodied greenhouse gas emissions and water consumption in concrete. International Journal of Life Cycle Assessment, 14(7), 621629. http://doi.org/10.1007/s11367-009-0105-5

Obuzor, G. N., Kinuthia, J. M., y Robinson, R. B. (2012). Soil stabilisation with limeactivated-GGBS-A mitigation to flooding effects on road structural layers/embankments constructed on floodplains. Engineering Geology, 151, 112-119. http://doi.org/10.1016/J.ENGGEO.2012.09.010

Oti, J. E., Kinuthia, J. M., y Bai, J. (2008). Using slag for unfired-clay masonry-bricks. Proceedings of the Institution of Civil Engineers - Construction Materials, 161(4), 147155. http://doi.org/10.1680/coma.2008.161.4.147

Oti, J. E., Kinuthia, J. M., y Bai, J. (2009a). Engineering properties of unfired clay masonry bricks. Engineering Geology, 107(3-4), 130-139.

http://doi.org/10.1016/J.ENGGEO.2009.05.002

Oti, J. E., Kinuthia, J. ., y Bai, J. (2009b). Compressive strength and microstructural analysis of unfired clay masonry bricks. Engineering Geology, 109(3-4), 230-240. http://doi.org/10.1016/J.ENGGEO.2009.08.010

Oti, J. E., Kinuthia, J. M., y Bai, J. (2010). Design thermal values for unfired clay bricks. Materials \& Design, 31(1), 104-112. http://doi.org/10.1016/J.MATDES.2009.07.011

Oti, J. E., y Kinuthia, J. M. (2012). Stabilised unfired clay bricks for environmental and sustainable use. Applied Clay Science, 58, 52-59. http://doi.org/10.1016/J.CLAY.2012.01.011

Oti, J. E., Kinuthia, J. M., y Robinson, R. B. (2014). The development of unfired clay building material using Brick Dust Waste and Mercia mudstone clay. Applied Clay Science, 102, 148-154. http://doi.org/10.1016/J.CLAY.2014.09.031

Ouellet-Plamondon, C., y Habert, G. (2015). Life cycle assessment (LCA) of alkali-activated cements and concretes. Handbook of Alkali-Activated Cements, Mortars and Concretes, 663-686. http://doi.org/10.1533/9781782422884.5.663

Ouhadi, V. R., y Yong, R. N. (2003). The role of clay fractions of marly soils on their post stabilization failure. Engineering Geology, 70(3-4), 365-375.

http://doi.org/10.1016/S0013-7952(03)00104-2 
Ouhadi, V. R., y Yong, R. N. (2008). Ettringite formation and behaviour in clayey soils. Applied Clay Science, 42(1-2), 258-265. http://doi.org/10.1016/J.CLAY.2008.01.009

Özalp, F., Yılmaz, H. D., Kara, M., Kaya, Ö., y Şahin, A. (2016). Effects of recycled aggregates from construction and demolition wastes on mechanical and permeability properties of paving stone, kerb and concrete pipes. Construction and Building Materials, 110, 17-23. http://doi.org/10.1016/J.CONBUILDMAT.2016.01.030

Pacheco-Torgal, F., Castro-Gomes, J., y Jalali, S. (2008). Alkali-activated binders: A review. Part 2. About materials and binders manufacture. Construction and Building Materials, 22(7), 1315-1322. http://doi.org/10.1016/J.CONBUILDMAT.2007.03.019

Pacheco-Torgal, F. (2014). Eco-efficient construction and building materials research under the EU Framework Programme Horizon 2020. Construction and Building Materials, 51, 151-162. http://doi.org/10.1016/J.CONBUILDMAT.2013.10.058

Passuello, A., Rodríguez, E. D., Hirt, E., Longhi, M., Bernal, S. A., Provis, J. L., y Kirchheim, A. P. (2017). Evaluation of the potential improvement in the environmental footprint of geopolymers using waste-derived activators. Journal of Cleaner Production, 166, 680-689. http://doi.org/10.1016/J.JCLEPRO.2017.08.007

Pavoine, A., Brunetaud, X., y Divet, L. (2012). The impact of cement parameters on Delayed Ettringite Formation. Cement and Concrete Composites, 34(4), 521-528. http://doi.org/10.1016/J.CEMCONCOMP.2011.11.012

Phoo-ngernkham, T., Hanjitsuwan, S., Suksiripattanapong, C., Thumrongvut, J., Suebsuk, J., y Sookasem, S. (2016). Flexural strength of notched concrete beam filled with alkaliactivated binders under different types of alkali solutions. Construction and Building Materials, 127, 673-678. http://doi.org/10.1016/j.conbuildmat.2016.10.053

Phoo-ngernkham, T., Hanjitsuwan, S., Li, L., Damrongwiriyanupap, N., y Chindaprasirt, P. (2018). Adhesion characterisation of Portland cement concrete and alkali-activated binders. Advances in Cement Research, 0(0), 1-11. http://doi.org/10.1680/jadcr.17.00122

Provis, J. L. (2017). Alkali-activated materials. Cement and Concrete Research. http://doi.org/10.1016/J.CEMCONRES.2017.02.009

Prusinski, J. R., Marceau, M. L., y Van Geem, M. G. (2006). Life cycle inventory of slag cement concrete. Eighth CANMET/ACI International Conference on Recent Advances in Concrete Technology, American Concrete Institute: Montreal, Canada, 362.

Puertas, F., Torres-Carrasco, M., y Alonso, M. M. (2015). Reuse of urban and industrial waste glass as a novel activator for alkali-activated slag cement pastes: a case study. Handbook of Alkali-Activated Cements, Mortars and Concretes, 75-109. http://doi.org/10.1533/9781782422884.1.75

Rahhal, V., y Talero, R. (2014). Very early age detection of ettringite from pozzolan origin. Construction and Building Materials, 53, 674-679. 
http://doi.org/10.1016/J.CONBUILDMAT.2013.10.082

Rajasekaran, G. (2005). Sulphate attack and ettringite formation in the lime and cement stabilized marine clays. Ocean Engineering, 32(8-9), 1133-1159.

http://doi.org/10.1016/J.OCEANENG.2004.08.012

Raut, S. P., Ralegaonkar, R. V., y Mandavgane, S. A. (2011). Development of sustainable construction material using industrial and agricultural solid waste: A review of wastecreate bricks. Construction and Building Materials, 25(10), 4037-4042.

http://doi.org/10.1016/J.CONBUILDMAT.2011.04.038

Rodríguez, C., Parra, C., Casado, G., Miñano, I., Albaladejo, F., Benito, F., y Sánchez, I. (2016). The incorporation of construction and demolition wastes as recycled mixed aggregates in non-structural concrete precast pieces. Journal of Cleaner Production, 127, 152-161. http://doi.org/10.1016/J.JCLEPRO.2016.03.137

Schackow, A., Stringari, D., Senff, L., Correia, S. L., y Segadães, A. M. (2015). Influence of fired clay brick waste additions on the durability of mortars. Cement and Concrete Composites, 62, 82-89. http://doi.org/10.1016/J.CEMCONCOMP.2015.04.019

Schorcht, F., Kourti, I., Scalet, B. M., Roudier, S., y Sancho, L. D. (2013). Best Available Techniques (BAT) Reference Document for the Production of Cement, Lime and Magnesium Oxide. Industrial Emissions Directive 2010/75/EU (Integrated Pollution Prevention and Control). J R C Reference Reports. http://doi.org/10.2788/12850

Seco, A., Ramírez, F., Miqueleiz, L., y García, B. (2011a). Stabilization of expansive soils for use in construction. Applied Clay Science, 51(3), 348-352.

http://doi.org/10.1016/J.CLAY.2010.12.027

Seco, A., Ramírez, F., Miqueleiz, L., García, B., y Prieto, E. (2011b). The use of nonconventional additives in Marls stabilization. Applied Clay Science, 51(4), 419-423. http://doi.org/10.1016/J.CLAY.2010.12.032

Seco, A., Ramirez, F., Miqueleiz, L., Urmeneta, P., García, B., Prieto, E., y Oroz, V. (2012). Types of Waste for the Production of Pozzolanic Materials - A Review. En IntechOpen (Ed.), Industrial Waste. Prof. Kuan-Yeow Show. http://doi.org/10.5772/36285

Seco, A., Urmeneta, P., Prieto, E., Marcelino, S., García, B., y Miqueleiz, L. (2017). Estimated and real durability of unfired clay bricks: Determining factors and representativeness of the laboratory tests. Construction and Building Materials, 131, 600-605. http://doi.org/10.1016/J.CONBUILDMAT.2016.11.107

Shi, C., Roy, D., y Krivenko, P. (2005). Alkali-Activated Cements and Concretes. CRC Press. Recuperado a partir de https://www.crcpress.com/Alkali-Activated-Cements-andConcretes/Shi-Roy-Krivenko/p/book/9780415700047

Shi, C., y Jiménez, A. F. (2011). New cements for the 21st century: The pursuit of an alternative to Portland cement. Cement and Concrete Research, 41(7), 750-763. http://doi.org/10.1016/J.CEMCONRES.2011.03.016 
Shi, X., Yang, Z., Liu, Y., \& Cross, D. (2011). Strength and corrosion properties of Portland cement mortar and concrete with mineral admixtures. Construction and Building Materials, 25(8), 3245-3256. https://doi.org/10.1016/J.CONBUILDMAT.2011.03.011

Silva, R. V., de Brito, J., y Dhir, R. K. (2014). Properties and composition of recycled aggregates from construction and demolition waste suitable for concrete production. Construction and Building Materials, 65, 201-217. http://doi.org/10.1016/J.CONBUILDMAT.2014.04.117

Talero, R. (2005). Performance of metakaolin and Portland cements in ettringite formation as determined by ASTM C 452-68: kinetic and morphological differences. Cement and Concrete Research, 35(7), 1269-1284. http://doi.org/10.1016/J.CEMCONRES.2004.10.002

Tasong, W. A., Wild, S., y Tilley, R. J. D. (1999). Mechanisms by which ground granulated blastfurnace slag prevents sulphate attack of lime-stabilised kaolinite. Cement and Concrete Research, 29(7), 975-982. http://doi.org/10.1016/S0008-8846(99)00007-1

Teh, S. H., Wiedmann, T., Castel, A., y de Burgh, J. (2017). Hybrid life cycle assessment of greenhouse gas emissions from cement, concrete and geopolymer concrete in Australia. Journal of Cleaner Production, 152, 312-320. http://doi.org/10.1016/J.JCLEPRO.2017.03.122

Turner, L. K., y Collins, F. G. (2013). Carbon dioxide equivalent (CO2-e) emissions: A comparison between geopolymer and OPC cement concrete. Construction and Building Materials, 43(October), 125-130. http://doi.org/10.1016/j.conbuildmat.2013.01.023

UE. (2008). Directiva 2008/98/CE del Parlamento Europeo y del Consejo, de 19 de noviembre de 2008 , sobre los residuos y por la que se derogan determinadas Directivas. Parlamento Europeo, 28 pags. (43 articulos). Recuperado a partir de http://eurlex.europa.eu/LexUriServ/LexUriServ.do?uri=OJ:L:2008:312:0003:01:ES:HTML

Uranjek, M., y Bokan-Bosiljkov, V. (2015). Influence of freeze-thaw cycles on mechanical properties of historical brick masonry. Construction and Building Materials, 84, 416428. http://doi.org/10.1016/J.CONBUILDMAT.2015.03.077

Vegas, I., Broos, K., Nielsen, P., Lambertz, O., y Lisbona, A. (2015). Upgrading the quality of mixed recycled aggregates from construction and demolition waste by using nearinfrared sorting technology. Construction and Building Materials, 75, 121-128. http://doi.org/10.1016/J.CONBUILDMAT.2014.09.109

Vieira, C. S., Pereira, P. M., y Lopes, M. de L. (2016). Recycled Construction and Demolition Wastes as filling material for geosynthetic reinforced structures. Interface properties. Journal of Cleaner Production, 124, 299-311. http://doi.org/10.1016/J.JCLEPRO.2016.02.115

Wild, S., Kinuthia, J. ., Jones, G. ., y Higgins, D. . (1998). Effects of partial substitution of lime with ground granulated blast furnace slag (GGBS) on the strength properties of 
lime-stabilised sulphate-bearing clay soils. Engineering Geology, 51(1), 37-53. http://doi.org/10.1016/S0013-7952(98)00039-8

Xeidakis, G. S. (1996a). Stabilization of swelling clays by $\mathrm{Mg}(\mathrm{OH}) 2$. Changes in clay properties after addition of Mg-hydroxide. Engineering Geology, 44(1-4), 107-120. http://doi.org/10.1016/S0013-7952(96)00047-6

Xeidakis, G. S. (1996b). Stabilization of swelling clays by $\mathrm{Mg}(\mathrm{OH}) 2$. Factors affecting hydroxy-Mg-interlayering in swelling clays. Engineering Geology, 44(1-4), 93-106. http://doi.org/10.1016/S0013-7952(96)00046-4

Xuan, D. X., Molenaar, A. A. A., y Houben, L. J. M. (2015). Evaluation of cement treatment of reclaimed construction and demolition waste as road bases. Journal of Cleaner Production, 100, 77-83. http://doi.org/10.1016/J.JCLEPRO.2015.03.033

Xuan, D. X., Molenaar, A. A. A., y Houben, L. J. M. (2016). Deformation behavior of cement treated demolition waste with recycled masonry and concrete subjected to drying and temperature change. Cement and Concrete Composites, 68, 27-34.

http://doi.org/10.1016/J.CEMCONCOMP.2016.02.005

Yang, K.-H., Cho, A.-R., y Song, J.-K. (2012). Effect of water-binder ratio on the mechanical properties of calcium hydroxide-based alkali-activated slag concrete. Construction and Building Materials, 29, 504-511.

http://doi.org/10.1016/J.CONBUILDMAT.2011.10.062

Yarbaşı, N., Kalkan, E., y Akbulut, S. (2007). Modification of the geotechnical properties, as influenced by freeze-thaw, of granular soils with waste additives. Cold Regions Science and Technology, 48(1), 44-54. http://doi.org/10.1016/J.COLDREGIONS.2006.09.009

Yong, R. N., y Ouhadi, V. R. (2007). Experimental study on instability of bases on natural and lime/cement-stabilized clayey soils. Applied Clay Science, 35(3-4), 238-249. http://doi.org/10.1016/J.CLAY.2006.08.009

Zhang, L. (2013). Production of bricks from waste materials - A review. Construction and Building Materials, 47, 643-655.

http://doi.org/10.1016/J.CONBUILDMAT.2013.05.043

Zhang, Z., Provis, J. L., Zou, J., Reid, A., y Wang, H. (2016). Toward an indexing approach to evaluate fly ashes for geopolymer manufacture. Cement and Concrete Research, 85, 163-173. http://doi.org/10.1016/J.CEMCONRES.2016.04.007 